\title{
Model study of the cross-tropopause transport of biomass burning pollution
}

\author{
B. N. Duncan ${ }^{1}$, S. E. Strahan ${ }^{1}$, Y. Yoshida ${ }^{1}$, S. D. Steenrod ${ }^{1}$, and N. Livesey ${ }^{2}$ \\ ${ }^{1}$ Goddard Earth Sciences and Technology Center, University of Maryland, Baltimore County, Baltimore, Maryland, USA \& \\ The Atmospheric Chemistry and Dynamics Branch, NASA Goddard Space Flight Center, Greenbelt, Maryland, USA \\ ${ }^{2}$ Jet Propulsion Laboratory, California Institute of Technology, Pasadena, California, USA
}

Received: 25 January 2007 - Published in Atmos. Chem. Phys. Discuss.: 15 February 2007

Revised: 8 May 2007 - Accepted: 4 July 2007 - Published: 17 July 2007

\begin{abstract}
We present a modeling study of the troposphereto-stratosphere transport (TST) of pollution from major biomass burning regions to the tropical upper troposphere and lower stratosphere (UT/LS). TST occurs predominately through 1) slow ascent in the tropical tropopause layer (TTL) to the LS and 2) quasi-horizontal exchange to the lowermost stratosphere (LMS). We show that biomass burning pollution regularly and significantly impacts the composition of the TTL, LS, and LMS. Carbon monoxide (CO) in the LS in our simulation and data from the Aura Microwave Limb Sounder (MLS) shows an annual oscillation in its composition that results from the interaction of an annual oscillation in slow ascent from the TTL to the LS and seasonal variations in sources, including a semi-annual oscillation in $\mathrm{CO}$ from biomass burning. The impacts of $\mathrm{CO}$ sources that peak when ascent is seasonally low are damped (e.g. Southern Hemisphere biomass burning) and vice-versa for sources that peak when ascent is seasonally high (e.g. extra-tropical fossil fuels). Interannual variation of CO in the UT/LS is caused primarily by year-to-year variations in biomass burning and the locations of deep convection. During our study period, 1994-1998, we find that the highest concentrations of CO in the UT/LS occurred during the strong 1997-1998 El Niño event for two reasons: i. tropical deep convection shifted to the eastern Pacific Ocean, closer to South American and African CO sources, and ii. emissions from Indonesian biomass burning were higher. This extreme event can be seen as an upper bound on the impact of biomass burning pollution on the UT/LS. We estimate that the 1997 Indonesian wildfires increased $\mathrm{CO}$ in the entire TTL and tropical LS (>60 mb) by more than $40 \%$ and $10 \%$, respectively, for several months. Zonal mean ozone increased and the hydroxyl radical decreased by as much as $20 \%$, increasing the lifetimes and, subsequently TST, of trace gases. Our results
\end{abstract}

Correspondence to: B. N. Duncan

(bryan.n.duncan@nasa.gov) indicate that the impact of biomass burning pollution on the UT/LS is likely greatest during an El Niño event due to favorable dynamics and historically higher burning rates.

\section{Introduction}

Schoeberl et al. (2006) identified the stratospheric "tape recorder" in carbon monoxide (CO), a seasonal oscillation in tropical lower stratospheric CO, in the Aura Microwave Limb Sounder (MLS) data. The term "tape recorder" was coined to describe the seasonal progression of tropical water vapor observed by the Upper Atmosphere Research Satellite (UARS) (Mote et al., 1996; Randel et al., 2001). Unlike the water vapor tape recorder which is controlled by seasonal variation in tropical upper tropospheric temperatures, Schoeberl et al. (2006) found that the CO tape recorder is linked to seasonal biomass burning, closely following the two maxima in the tropics that occur around March and September of each year (Duncan et al., 2003a). The main objectives of this modeling study are to discuss the troposphereto-stratosphere transport (TST) of trace gases from biomass burning and to assess the impact of the pollutants on the chemistry of the upper troposphere (UT) and lower stratosphere (LS). For this work, we use the Global Modeling Initiative's (GMI) combined stratosphere-troposphere chemistry and transport model (Combo CTM). The success of the Combo CTM in reproducing the general features of the $\mathrm{CO}$ tape recorder as discussed in Schoeberl et al. (2006) and the credible transport and chemistry in the LMS as shown by Strahan et al. (2007) demonstrates that this tool is appropriate to investigate the tropical TST process. We focus on CO, a tracer of transport, in this study; unlike water vapor, $\mathrm{CO}$ does not condense.

Biomass burning pollution is often lofted by convection to the UT (e.g. Pickering et al., 1996) as fires are typically set to clear fields and pastures in anticipation of the

Published by Copernicus Publications on behalf of the European Geosciences Union. 
arrival of seasonal rains. This pollution can enter the tropical tropopause layer (TTL), a region above the typical maximum vertical extent of convection $(\sim 150 \mathrm{mb})$ and below the tropopause $(\sim 100 \mathrm{mb})$. Vertical motions to the tropopause in the TTL are associated with slow, large-scale ascent due to clear sky radiative heating (Folkins et al., 1999), which varies seasonally with, for instance, temperature and ozone (e.g. Folkins et al., 2006). The level of zero radiative heating (LZH) in the TTL at $\sim 125 \mathrm{mb}$ is generally lower near the equator and areas of frequent deep convection (Gettelman et al., 2004; Folkins et al., 2006). The LZH is most sensitive to water vapor, though it is also sensitive to ozone and carbon dioxide (Gettelman et al., 2004). Aerosols also impact the radiative budget of the troposphere directly and indirectly by modifying clouds. Consequently, biomass burning pollutants have the potential to impact the dynamics of the UT/LS, including TST.

Newell and Gould-Stewart (1981) postulated the existence of a "stratospheric fountain", an area where tropospheric air preferentially enters the stratosphere, over Indonesia and India during their respective monsoon seasons. Their hypothesis has generated considerable debate over the existence of a fountain (e.g. Dessler, 1998; Sherwood, 2000; Hatsushika and Yamazaki, 2003). Fueglistaler et al. (2004), using trajectory calculations, found that $80 \%$ of their trajectories that ascended to the LS entered the TTL over the western Pacific "Warm Pool", an area with high sea surface temperatures (SSTs) and deep convection. The air in the TTL typically resides there for several weeks and travels $\sim 5000-10000 \mathrm{~km}$ before crossing the tropopause. The preferred locations of TST are the western Pacific Ocean, India, and the Indian Ocean.

Biomass burning pollution has been observed to be transported by the southern subtropical jet (e.g. Folkins et al., 1997; Chatfield et al., 2002; Staudt et al., 2002), where it can enter the lowermost stratosphere (LMS; i.e. the region below the $380 \mathrm{~K}$ potential temperature surface, but above the extratropical tropopause), via quasi-horizontal exchange (Holton et al., 1995; Levine et al., 2007). During winter, mixing is seasonally low due to a strong gradient in potential vorticity (PV). In summer, PV gradients are much weaker and transient wave disturbances can grow in amplitude, break, and cause irreversible mixing between the tropical UT and the LMS (Chen, 1995; Haynes and Shuckburgh, 2000). Such disturbances are common in the northern summer near the Asian and Mexican monsoon circulations and allow significant exchange between the tropics and midlatitudes between 100-200 mb (Chen, 1995). However, the LMS is characterized by descending air, so that most of the pollution will eventually return to the troposphere (Schoeberl et al., 2004).

$\mathrm{Li}$ et al. (2005) and Fu et al. (2006) showed that MLS $\mathrm{CO}$ is high over the Tibetan Plateau during the Indian monsoon in summer. The lofting of pollution to the UT during the Asian monsoon is also evident in the MOPITT CO data (Kar et al., 2004). Dethof et al. (1999) proposed that TST to the LMS occurs when midlatitude synoptic-scale tropospheric cyclones, just north of the Tibetan plateau, interact with the monsoon circulation. Fu et al. (2006) found that convection over the Tibetan plateau is deeper than over the monsoon area, detraining more air near the tropopause. That is, this pathway is a short-circuit to the normal pathway of slow ascent in the TTL.

We do not believe that direct injection of biomass burning pollution above the tropical tropopause via convection is an important transport pathway for trace gases with lifetimes that are greater than the time-scale of transport to the tropopause (i.e. $>2-3$ weeks) via slow ascent. Liu and Zipser (2005) analyzed five years of TRMM data, concluding that $1.3 \%$ of tropical convection systems reach $14 \mathrm{~km}$ and $0.1 \%$ possibly penetrates the tropopause (i.e. $380 \mathrm{~K}$ potential temperature). They found that overshooting deep convection occurs predominantly over central Africa, but also over Indonesia and South America. Rossow and Pearl (2007) analyzed 22 years of ISCCP cloud data, reporting a slightly higher penetration rate of tropical deep convection than Liu and Zipser (2005): $\sim 2 \%$ in the TTL and $\sim 1 \%$ into the LS. They found that almost all large convective systems (i.e. radii $>500 \mathrm{~km}$ ) have convection that penetrates into the TTL and almost all systems with radii $>1000 \mathrm{~km}$ reach the cold-point tropopause. Despite local zones of deep convection penetrating the stratosphere, tropical convective systems are not responsible for depositing pollutants at the tropopause. Instead, convective systems largely die out at $350 \mathrm{~K}$ and largescale ascent in the TTL brings air up to the tropical LS (i.e. $\geq 380 \mathrm{~K}$ potential temperature). To our knowledge, pyrocumulonimbus injection into the tropical LS has not been observed as it has in the boreal regions where the tropopause is lower (e.g. Jost et al., 2004; Livesey et al., 2004; Fromm et al., 2005).

In this paper, we will show that biomass burning pollution does indeed reach the LS, changing the composition of chemically and radiatively important trace gases there. In Sect. 2, we describe the Combo CTM and the meteorological fields used to drive its transport. We present a simulation evaluation in Sect. 3. In Sect. 4, we identify the major TST pathways of biomass burning pollution using the 1997 Indonesian fires as an example; we assess the impact of the pollution on the composition of the UT/LS. In Sect. 5, we estimate the contributions of pollution from several sources, including interannual variability (IAV), to the oscillation of CO in the UT/LS. A summary of conclusions is given in Sect. 6.

\section{Global modeling initiative combined stratosphere- troposphere CTM}

The Combo CTM was developed from the stratospheric CTM described by Rotman et al. (2001) and Douglass et al. (2004). Initial descriptions of the Combo CTM can be found in Ziemke et al. (2006). Strahan et al. (2007) and 
Table 1. Annual Emissions in the Combo CTM.

\begin{tabular}{|c|c|c|c|c|c|c|c|c|c|c|c|c|}
\hline Source & $\begin{array}{l}\mathrm{NO}_{\mathrm{x}} \\
\mathrm{Tg} \\
\mathrm{N}\end{array}$ & $\begin{array}{l}\mathrm{CO} \\
\mathrm{Tg} \\
\text { direct }\end{array}$ & $\begin{array}{l}\mathrm{CO} \\
\mathrm{Tg} \\
\text { indirect }\end{array}$ & $\begin{array}{l}\text { MEK } \\
\text { Tg C }\end{array}$ & $\begin{array}{l}\text { PRPE } \\
\text { Tg C }\end{array}$ & $\begin{array}{l}\mathrm{C}_{2} \mathrm{H}_{6} \\
\mathrm{Tg} \mathrm{C}\end{array}$ & $\begin{array}{l}\mathrm{C}_{3} \mathrm{H}_{8} \\
\mathrm{Tg} \mathrm{C}\end{array}$ & $\begin{array}{l}\text { ALK4 } \\
\text { Tg C }\end{array}$ & $\begin{array}{l}\text { ALD2 } \\
\text { Tg C }\end{array}$ & $\begin{array}{l}\mathrm{CH}_{2} \mathrm{O} \\
\mathrm{Tg} \mathrm{C}\end{array}$ & $\begin{array}{l}\text { ISOP } \\
\text { Tg C }\end{array}$ & $\begin{array}{l}\text { NMHC } \\
\text { Tg C }\end{array}$ \\
\hline Soils & 6.6 & - & & - & - & - & - & - & - & - & - & - \\
\hline Vegetation & - & - & $150.5^{\mathrm{a}}$ & - & 10.9 & - & - & - & - & - & 380.0 & 390.9 \\
\hline Aircraft ${ }^{b}$ & 0.6 & - & & - & - & - & - & - & - & - & - & - \\
\hline Lightning $^{\mathrm{c}}$ & 5.0 & - & & - & - & - & - & - & - & - & - & - \\
\hline Fossil Fuel ${ }^{b}$ & 23.6 & $393.8^{d}$ & $7.9^{\mathrm{e}}$ & 0.8 & 7.9 & 5.3 & 5.7 & 25.2 & - & - & - & 44.9 \\
\hline Biomass $^{c}$ & 6.5 & 439.3 & $22.0^{\mathrm{e}}$ & 3.6 & 3.9 & 1.9 & 0.7 & 0.6 & 2.6 & 1.9 & - & 15.3 \\
\hline Biofuel $^{b}$ & 2.2 & 160.3 & $13.8^{\mathrm{e}}$ & 1.3 & 6.3 & 2.0 & 0.9 & 0.8 & 0.7 & 0.5 & - & 12.4 \\
\hline Total & 44.5 & 993.4 & 194.2 & 5.8 & 29.0 & 9.3 & 7.3 & 26.6 & 3.3 & 2.4 & 380.0 & 463.5 \\
\hline
\end{tabular}

a Emissions from the oxidation of 1) biogenic methanol (100 Tg CO) and 2) monoterpenes (50.5 Tg CO).

b Annual mean emissions.

c Monthly mean emissions.

d Scaled $10 \%$ higher in summer and $10 \%$ lower in winter.

e $\mathrm{CO}$ derived from photochemical oxidation of NMHC not accounted for in anthropogenic NMHC emission inventory.

$\mathrm{PRPE}=$ lumped $\geq \mathrm{C}_{3}$ alkenes; ALK4 $=$ lumped $\geq \mathrm{C}_{4}$ alkanes; $\mathrm{ALD} 2=$ acetaldehyde; ISOP $=$ isoprene.

references therein describe the UT/LS processes in the simulation.

\subsection{Chemistry}

The chemical mechanism is obtained by combining tropospheric and stratospheric mechanisms and includes 117 species, 322 chemical reactions, and 81 photolysis reactions. The chemical mass balance equations are integrated using the SMVGEAR II algorithm (Jacobson, 1995). The tropospheric mechanism includes a detailed description of tropospheric $\mathrm{O}_{3}-\mathrm{NO}_{\mathrm{x}}$-hydrocarbon chemistry (Bey et al., 2001). It has been updated with recent experimental data from Tyndall et al. (2001) and Sander et al. (2003), and data for the quenching reactions of $\mathrm{O}\left({ }^{1} \mathrm{D}\right)$ by $\mathrm{N}_{2}, \mathrm{O}_{2}$, and $\mathrm{H}_{2} \mathrm{O}$ (Ravishankara et al., 2002; Dunlea and Ravishankara, 2004). The stratospheric mechanism is described in Kinnison et al. (2001) and Douglass et al. (2004). A description of the polar stratospheric cloud parameterization is provided by Considine et al. (2000). Mixing ratio boundary conditions were imposed for halogen source gases for conditions appropriate for the simulation year as described in Strahan et al. (2007) and Douglass et al. (2004).

Photolysis frequencies are computed using the Fast-JX radiative transfer algorithm, which combines the Fast-J tropospheric scheme described in Wild et al. (2000) with the FastJ2 stratospheric scheme of Bian and Prather (2002) (Michael Prather, personal communication, 2005). The algorithm treats both Rayleigh scattering as well as Mie scattering by clouds and aerosol.

The Combo CTM simulates the radiative and heterogeneous chemical effects of sulfate, dust, sea-salt, organic car- bon and black carbon aerosol on tropospheric photochemistry. The monthly-averaged aerosol surface area distributions were obtained from the Goddard Chemistry Aerosol Radiation and Transport (GOCART) model for 2001 (Chin et al., 2002). The aerosol fields were coupled to the Combo CTM as described by Martin et al. (2003). The reaction probability for $\mathrm{N}_{2} \mathrm{O}_{5}$ is a function of aerosol type, relative humidity, and temperature, and is significantly lower than earlier estimates (Evans and Jacob, 2005).

\subsection{Emissions}

Table 1 summarizes the annual anthropogenic and natural emissions.

\subsubsection{Anthropogenic emissions}

The base fossil fuel emissions are described by Bey et al. (2001) and Duncan et al. ("The global budget of CO, 1988-1997: source estimates and validation with a global model", submitted manuscript; hereafter referred to as Duncan et al., 2007) that includes $\mathrm{NO}_{\mathrm{x}}$ emissions from the Global Emission Inventory Activity (GEIA) (Benkovitz et al., 1996) and non-methane hydrocarbon (NMHC) emissions from Piccot et al. (1992). The base emissions, which are for 1985 , are scaled to reflect emissions in 1995 as described in Bey et al. (2001). Seasonal variation $( \pm 10 \%)$ is applied for CO poleward of $35^{\circ} \mathrm{N}$ to reflect higher automobile emissions in winter (Duncan et al., 2007). The monthly mean emissions of $\mathrm{NO}_{\mathrm{x}}$ from aircraft are from the inventory of Baughcum et al. (1996) and Metwally (1995), representing 1995 
conditions. Biofuel emissions are estimated from the inventory and emission factors of Yevich and Logan (2003).

For the Indonesian wildfire experiment in Sect. 4, we use the Global Fire Emissions Database version 2 (GFEDv2; van der Werf et al., 2006). We do not simulate the radiative and heterogeneous chemical impacts of the aerosols from the Indonesian fires. Duncan et al. (2003b) showed that they decreased $\mathrm{OH}$ by about $10 \%$ over much of the Indian Ocean with a concomitant increase in $\mathrm{CO}$ by $<10 \%$. Neglecting the effect of these aerosols on CO is not important for our study as our purpose is to estimate if the change in the composition of trace gases in the TTL and LS is substantial.

For the experiments in Sect. 5, we use the biomass burning emissions inventory presented in Duncan et al. (2003a), which represents a mean for 1980 to 1990 . Categories in the inventory are deforestation, shifting cultivation, agricultural residues burned in the field, savanna burning, and forest fires. Trace gas emission factors are from Andreae and Merlet (2001).

In the inventories described here, we do not directly account for the emissions of several NMHC, such as aromatics, from fossil fuels, biofuels, and biomass burning. We estimate the production of $\mathrm{CO}$ from these NMHC by multiplying the emission rate of each NMHC in a given inventory by a yield of CO per carbon oxidized, as described in Duncan et al. (2007). Applying these yields, we find that oxidation of anthropogenic NMHC results in a source of $\mathrm{CO}$ that is $2 \%$, $8.6 \%$ and $5 \%$ of the direct $\mathrm{CO}$ emission from fossil fuels, biofuels and biomass burning, respectively. The direct emissions from these three sources are increased to account for the indirect source from oxidation of co-emitted NMHC.

\subsubsection{Natural emissions}

The distribution of isoprene emissions from vegetation is based on a modified version of the inventory of Guenther et al. (1995) and is dependent on solar radiation and temperature. The principal modifications are described by Wang et al. (1998) and Bey et al. (2001). The global emission rate of the modified inventory is $380 \mathrm{Tg} \mathrm{C} / \mathrm{y}$, which is about $25 \%$ lower than the inventory of Guenther et al. (1995), $503 \mathrm{Tg}$ $\mathrm{C} / \mathrm{y}$. We do not simulate the transport and chemistry of monoterpenes and methanol directly, but we do account for the $\mathrm{CO}$ produced from their oxidation following Duncan et al. (2007).

The lightning source is set to $5.0 \mathrm{Tg} \mathrm{N} / \mathrm{y}$ and is horizontally distributed using monthly mean lightning emissions based on the locations and heights of deep convective clouds from the ISCCP cloud climatology (Price et al., 1997). Lightning flash rates used in constructing these emissions are based on the cloud-top height parameterization of Price and Rind (1992). The vertical distribution of the $\mathrm{NO}_{\mathrm{x}}$ is specified by the profiles derived from cloud-resolved convection simulations of Pickering et al. (1998).
We compute emissions of NO by soil microbes as described in Wang et al. (1998). The emissions are a function of vegetation type (Olson, 1992), temperature, fertilizer usage, and precipitation history. The scheme simulates the oxidation of $\mathrm{NO}$ to $\mathrm{NO}_{2}$ and subsequent uptake by vegetation within the canopy (Jacob and Bakwin, 1991).

\subsubsection{Other}

Methane mixing ratios are forced at the surface with annual mean values for 2001 using National Oceanic and Atmospheric Administration (NOAA) Global Monitoring Division (GMD) measurements (Dlugokencky et al., 1998). They are zonally uniform in four semi-hemispheres. Monthlyaveraged acetone concentrations are specified following Jacob et al. (2002).

\subsection{Transport}

In our study we use five years of meteorological fields from the Goddard Modeling and Assimilation Office (GMAO) GEOS-4 general circulation model (GEOS-4-GCM) (Bloom et al., 2005), using SSTs representing 1994 to 1998. They have been regridded to 42 vertical levels with a lid at $0.01 \mathrm{hPa}$; there are $\sim 20$ levels from the surface to the LS $(>60 \mathrm{mb})$ with $\sim 1 \mathrm{~km}$ resolution in the UT/LS. The horizontal resolution is $2^{\circ}$ latitude $\times 2.5^{\circ}$ longitude. The Combo CTM transports 71 of the 117 species in the chemical mechanism, using the advection scheme of Lin and Rood (1996) and uses the Harvard wet scavenging algorithm (Liu et al., 2001) and the dry deposition scheme described by Wang et al. (1998), which follows the methodology of Wesely et al. (1985).

A description of convective transport is given in the appendix of Rasch et al. (1997). The scheme uses the following meteorological fields as input: cloud mass fluxes, entrainment and detrainment fluxes, and large-scale downwelling. Both shallow and deep convection are considered, following the algorithms of Hack (1994) and Zhang and McFarlane (1995). Convection in the equatorial tropics typically dies out by $350 \mathrm{~K}$ in our simulation, with none reaching $360 \mathrm{~K}$; consequently, it does not penetrate the TTL and LS in our simulations presented here.

\section{Evaluation of the Combo CTM simulation}

\subsection{Summary of previous work}

Schoeberl et al. (2006) found that the MLS CO tape recorder is qualitatively similar to that of the simulation presented here, implying that slow ascent in the tropics and horizontal mixing in the UT/LS are credible. Strahan et al. (2007) evaluated the Combo CTM's performance in the UT/LS using a variety of satellite and aircraft-derived transport diagnostics. 
They showed that the simulation has credible seasonallyvarying composition and transport in the LS, including the LMS, as well as realistic coupling between the extra-tropical troposphere and stratosphere. Ziemke et al. (2006) compared OMI/MLS tropospheric column ozone (TCO) observations with those of the simulation, finding that the two agree well both spatially and seasonally, including for the South Atlantic maximum and western Pacific minimum. The simulated ozone is typically higher from $30-40^{\circ}$ latitude in both hemispheres, particularly the northern hemisphere $(\mathrm{NH})$, and too low over the Warm Pool in all seasons. Ozonesonde data support that the simulated TCO from $30-40^{\circ} \mathrm{N}$ is too high.

\subsection{Troposphere}

In this study, we use $\mathrm{CO}$ as a tracer of transport as its chemical lifetime is 1-2 months in the tropical and subtropical UT/LS, which is longer than the timescales of most transport processes, including TST ( $\sim 2-3$ weeks); see discussion in Sect. 4.2. The evaluation of our 5-yr simulation (1994-1998 SSTs) is for $\mathrm{CO}$ and $\mathrm{OH}$, as reaction with $\mathrm{OH}$ is the primary sink for CO. Our evaluation is necessarily qualitative as we use climatological emissions and the meteorology represents no particular time, though it should capture IAV due to SSTs associated with the phases of the El Niño/Southern Oscillation (ENSO).

Figure 1 shows a comparison of simulated $\mathrm{CO}$ and NOAA GMD surface observations for 1994-1998 (Novelli et al., 1992, 1998). Statistical information for each station is given in Table 2. The simulation is systematically biased low at most stations in local winter/spring when the burden is typically at an annual maximum. Transport deficiencies may play a role as the seasonal maximum in the tropics is largely due to the long-range transport of pollution from biomass burning and fossil fuel source regions; this issue is discussed in more detail in Duncan et al. (2007). The simulated CO generally compares well to observations in local summer/fall when regional photochemical production of $\mathrm{CO}$ becomes more important.

Another possible reason for the low bias is too high $\mathrm{OH}$, though this does not appear to be the case as the $\mathrm{CH}_{3} \mathrm{CCl}_{3}$ lifetime in our simulation is reasonable. The mean tropospheric $\mathrm{OH}$ for our simulation (1994 SSTs) is $0.98 \times 10^{6} \mathrm{molec} / \mathrm{cm}^{3}$, which is similar to that reported by Spivakovsky et al. (2000), $1.16 \times 10^{6} \mathrm{molec} / \mathrm{cm}^{3}$. The $\mathrm{CH}_{3} \mathrm{CCl}_{3}$ lifetime with respect to tropospheric $\mathrm{OH}$ is $6.1 \mathrm{y}$, which is similar to that reported by Prinn et al. (2005), 6.0 $(+0.5,-0.4) \mathrm{y}$, and Spivakovsky et al. (2000), $5.7 \mathrm{y}$. However, the lifetime provides less information on the quality of simulated $\mathrm{OH}$ outside of the lower tropospheric tropics; the rate constant for reaction of $\mathrm{OH}$ with $\mathrm{CH}_{3} \mathrm{CCl}_{3}$ is strongly temperature dependent. On the other hand, the rate constant for the reaction of $\mathrm{OH}$ with $\mathrm{CO}$ is only weakly pressure dependent. That is, $\mathrm{CO}$ loss is efficient throughout the tropical troposphere.

\section{$3.3 \mathrm{UT} / \mathrm{LS}$}

There are two long-term aircraft missions, Japan Airlines (JAL; Matsueda et al., 1998) and Measurements of OZone by Airbus In-service airCraft (MOZAIC; Marenco et al., 1998; Nedelec et al., 2003; Nedelec et al., 2005: www.aero. obs-mip.fr/mozaic), that measure $\mathrm{CO}$ in the UT. Figure 2 shows a seasonal comparison of the simulated $\mathrm{CO}$ and the JAL data (9-13 km) from 1994-1998 for flights from Tokyo, Japan to Sydney, Australia. The data include 19 to 27 flights per season; however, we did not use data from September 1997 to May 1998 as CO was abnormally high from the Indonesian fires (Matsueda et al., 1999). The simulation captures the observed latitudinal gradient in mean $\mathrm{CO}$ and simulates much of the observed IAV. For instance, the simulated $\mathrm{CO}$ and observations show IAV in the northern subtropics from March through May, a time when the UT is impacted by biomass burning pollution from Southeast Asia (e.g. Jacob et al., 2003). In the data, there is strong IAV from September through November in the southern tropics, which is associated with the IAV of biomass burning emissions; the simulated CO does not show strong IAV as we use climatological emissions. Figure 3 shows a histogram comparison of the simulation and MOZAIC flights between Europe and East Asia. Consistent with the GMD measurements, the data show that the simulated $\mathrm{CO}$ is often biased low, though the spatial and temporal distributions are similar to the data.

We show a comparison of the MLS CO data product (version 2/level 2; Livesey et al., "Validation of Aura Microwave Limb Sounder $\mathrm{O}_{3}$ and $\mathrm{CO}$ observations in the upper troposphere and lower stratosphere", submitted manuscript, 2007) for March 2005 with the simulated CO (1994-1998 mean) in Fig. 4 in the UT/LS. Figure 5 shows a histogram of the simulated and MLS CO near the tropical tropopause $(\sim 100 \mathrm{mb})$ for four months in 2005. We use a three $\mathrm{h}$ average (noon15:00 local time) of the simulated CO as the Aura satellite overpass time is approximately 13:45 local time.

There are four issues of importance for this comparison. First, the vertical resolution of the MLS CO data in the UT/LS is $\sim 4-5 \mathrm{~km}$ (Filipiak et al., 2005), so we averaged the simulated $\mathrm{CO}$ over three vertical levels to obtain a similar layer thickness. The coarse vertical resolution limits use of the MLS CO data to obtain information on the transport pathways in the UT/LS, a region with strong vertical gradients. For instance, the $100 \mathrm{mb}$ level of the MLS data product may represent an average of a layer reaching from below the TTL into the LS. Second, the MLS sampling is patchy and overpasses do not overlap in the tropics. Therefore, the "daily" product, which has global coverage, is a composite of multiple days of observations. Third, the instrument precision is \pm 20 ppbv, a significant fraction of the expected variability in CO in the UT/LS. Consequently, it is necessary to average multiple days to garner useful geophysical information from the data (i.e. minimize random instrument noise; Filipiak et al., 2005). Currently, there are $\sim 100$ days of processed 

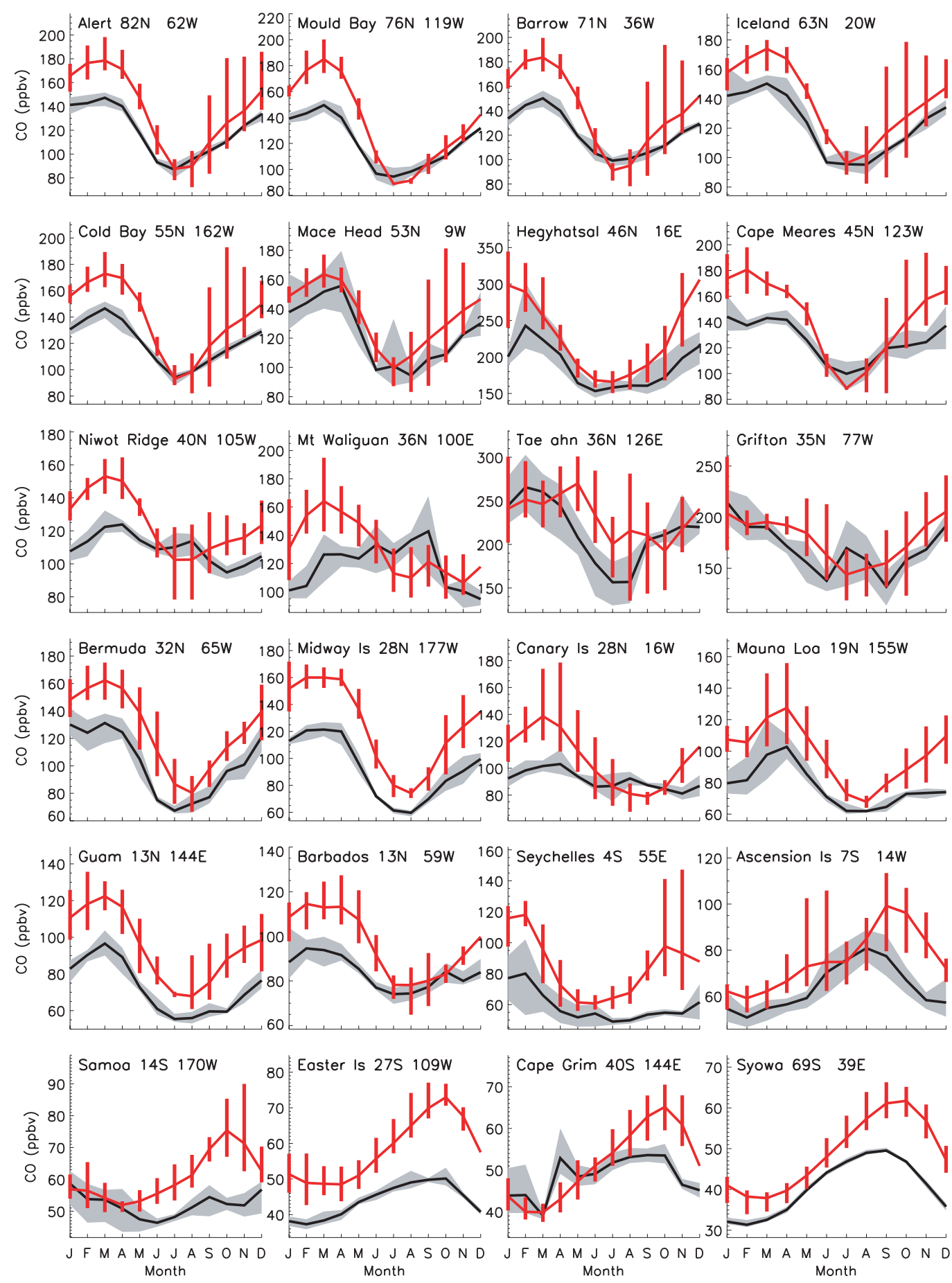

Fig. 1. Comparison of mean (1994-1998) CO from the simulation (black line) and GMD observations (red line). The red vertical bars and gray shaded area show the range of the monthly-averaged $\mathrm{CO}$ from the observations and the simulation, respectively, for the five years. Station locations are shown in Table 2.

data available in 2004 and 2005. Three months have about 10 days of data with which to create a "monthly" average. Fourth, the MLS data are known to be about two times too high as compared to observations in the UT, though this bias decreases somewhat with altitude (Filipiak et al., 2005). For example, the MLS data at $68 \mathrm{mb}$ in the tropics is $>40 \mathrm{ppbv}$, while observations from the Stratosphere Troposphere Exchange Project (STEP) field campaign in early 1987 found 
Table 2. Statistical Comparison of the Simulation with GMD Observations (1994-1998).

\begin{tabular}{|c|c|c|c|c|c|c|c|c|c|}
\hline $\begin{array}{l}\text { Station } \\
\text { ID }\end{array}$ & Station Location & $\begin{array}{l}\text { Lat } \\
\text { deg }\end{array}$ & $\begin{array}{l}\text { Lon } \\
\text { deg }\end{array}$ & $\begin{array}{l}\text { Alt } \\
\mathrm{m}\end{array}$ & $\mathrm{N}^{\mathrm{a}}$ & $\begin{array}{l}\Delta \text { b } \\
\text { ppbv }\end{array}$ & $\begin{array}{ll}\Delta & \mathrm{c} \\
\% & \end{array}$ & $\begin{array}{l}\text { Std. Err. } \\
\text { ppbv }\end{array}$ & $\mathrm{R}^{2 \mathrm{e}}$ \\
\hline \multicolumn{10}{|c|}{ High N. Hemisphere } \\
\hline $\mathrm{MBC}$ & Mould Bay, Canada & $76^{\circ} \mathrm{N}$ & $119^{\circ} \mathrm{W}$ & 58 & 41 & -17 & -10 & 2.5 & 0.88 \\
\hline BRW & Barrow, Alaska & $71^{\circ} \mathrm{N}$ & $36^{\circ} \mathrm{W}$ & 11 & 60 & -19 & -10 & 2.7 & 0.76 \\
\hline ICE & Heimaey, Iceland & $63^{\circ} \mathrm{N}$ & $20^{\circ} \mathrm{W}$ & 100 & 60 & -15 & -9.4 & 2.0 & 0.73 \\
\hline HUN & Hegyhatsal, Hungary & $46^{\circ} \mathrm{N}$ & $16^{\circ} \mathrm{E}$ & 248 & 60 & -40 & -15 & 5.3 & 0.47 \\
\hline \multicolumn{10}{|c|}{ N. America \& N. Atlantic } \\
\hline CMO & Cape Meares, Oregon & $45^{\circ} \mathrm{N}$ & $123^{\circ} \mathrm{W}$ & 30 & 51 & -18 & -9.4 & 3.1 & 0.66 \\
\hline NWR & Niwot Ridge, Colorado & $40^{\circ} \mathrm{N}$ & $105^{\circ} \mathrm{W}$ & 3475 & 60 & -15 & -10 & 2.2 & 0.28 \\
\hline ITN & Grifton, North Carolina & $35^{\circ} \mathrm{N}$ & $77^{\circ} \mathrm{W}$ & 505 & 60 & -8.8 & -3.1 & 3.9 & 0.18 \\
\hline CBA & Cold_Bay, Alaska & $55^{\circ} \mathrm{N}$ & $162^{\circ} \mathrm{W}$ & 25 & 60 & -17 & -10 & 2.3 & 0.76 \\
\hline TAP & Tae-ahn, S. Korea & $36^{\circ} \mathrm{N}$ & $126^{\circ} \mathrm{E}$ & 20 & 60 & -17 & -5.3 & 6.0 & 0.09 \\
\hline WLG & Mt. Waliguan, PRC & $36^{\circ} \mathrm{N}$ & $100^{\circ} \mathrm{E}$ & 3810 & 60 & -12 & -6.9 & 3.6 & 0.02 \\
\hline MID & Sand Island, Midway & $28^{\circ} \mathrm{N}$ & $177^{\circ} \mathrm{W}$ & 4 & 60 & -31 & -24 & 1.8 & 0.85 \\
\hline MLO & Mauna Loa, Hawaii & $19^{\circ} \mathrm{N}$ & $155^{\circ} \mathrm{W}$ & 3397 & 60 & -20 & -20 & 1.6 & 0.67 \\
\hline GMI & Guam, Mariana Islands & $13^{\circ} \mathrm{N}$ & $144^{\circ} \mathrm{E}$ & 2 & 60 & -22 & -22 & 1.4 & 0.77 \\
\hline \multicolumn{10}{|c|}{ S. Hemisphere Tropics } \\
\hline SEY & Mahe Island, Seychelles & $4^{\circ} \mathrm{S}$ & $55^{\circ} \mathrm{E}$ & 3 & 56 & -26 & -28 & 2.5 & 0.38 \\
\hline ASC & Ascension Island & $7^{\circ} \mathrm{S}$ & $14^{\circ} \mathrm{W}$ & 54 & 60 & -12 & -14 & 1.7 & 0.29 \\
\hline SMO & American Samoa & $14^{\circ} \mathrm{S}$ & $170^{\circ} \mathrm{W}$ & 42 & 60 & -7.9 & -12 & 1.2 & 0.01 \\
\hline \multicolumn{10}{|c|}{ Mid \& High S. Hemisphere } \\
\hline
\end{tabular}

${ }^{\text {a }} \mathrm{N}$ is the number of monthly mean observations.

$\mathrm{b}$ The bias is the mean of (simulated-observed)/observed for the entire time series.

c Mean bias (\%) relative to the mean observed CO.

d Standard error of mean bias $(\Delta)$.

${ }^{\mathrm{e}} \mathrm{R}$ is the linear correlation coefficient between the simulation and observations.

CO to be about 20 ppbv (Susan Strahan, personal communication), similar to the concentrations in our simulation (1525 ppbv).

Despite the limitations of the MLS CO data product and differing time periods of the observations and simulation, the horizontal distributions of $\mathrm{CO}$ are qualitatively similar to those in the simulation for March (Fig. 4). For instance, both the simulated and observed CO show maxima over Africa, south Asia, and South America, regions of deep convection, at $215 \mathrm{mb}$, and similar latitudinal gradients at all four pressure levels. We find comparable results for February and September, months with $\sim 10$ days of the MLS data product (not shown). One noticeable difference in Fig. 4 is the area of elevated CO over tropical Africa in the MLS data at $100 \mathrm{mb}$, which is not evident in the model. While this could indicate that the model is underestimating tropical convection there, we cannot draw any definitive conclusions based on the limitations discussed above. Figure 5 illustrates the data product's high bias with respect to the simulation, though it also shows that the spread of observations and the simulation have similar shapes year-round at $100 \mathrm{mb}$.

\section{Cross-tropopause transport pathways: 1997 Indone- sian wildfires}

In this section, we present a Combo CTM simulation of the 1997 Indonesian wildfires, one of the largest burning 


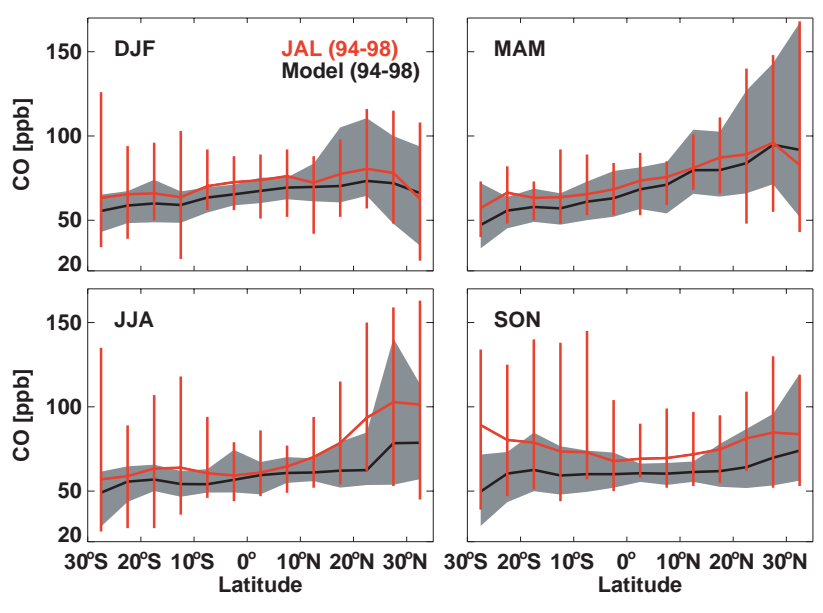

Fig. 2. A comparison of the JAL (red) and simulated (black) CO in the UT (9-13 km) for flights between Tokyo, Japan and Sydney, Australia from 1994-1998, except September 1997 to May 1998. The red vertical bars and gray shaded areas show the maximum and minimum seasonal average $\mathrm{CO}$ of the observations and the simulation, respectively, during the five years.
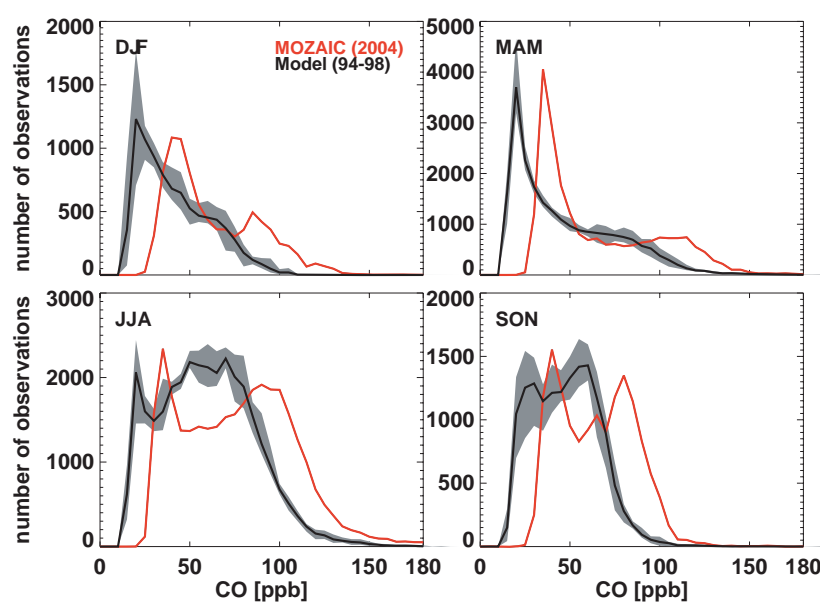

Fig. 3. A comparison of the MOZAIC (red) and simulated (black) $\mathrm{CO}$ for flights between East Asia and Europe. The gray shaded area shows the range of the seasonally-averaged simulated CO during 1994-1998. The aircraft data are from 2004.

events of the 20th century, to illustrate the principal crosstropopause pathways of biomass burning pollution. The fires began in August, peaked in September and October, and ended in November. Observations indicate that the wildfires had a profound impact on the composition of the tropical troposphere (Duncan et al., 2003b and references therein), including the UT (Matsueda et al., 1999; Matsueda and Inoue, 1999). The Indonesian wildfires occurred during the southern hemisphere (SH) burning season, so that the total biomass burning emissions of $\mathrm{CO}$ were about twice that of the Indonesian fires alone, or $\sim 70 \%$ of annual, global fos- sil fuel emissions. The purposes of this experiment are 1) to identify the major TST pathways of the pollution and 2) to understand the impact of this extreme biomass burning event on the composition of the UT/LS.

Duncan et al. (2003b) detailed the tropospheric transport pathways of the pollution. The Walker Circulation was weak and not well organized, which is typical of El Niño conditions. Consequently, the prevailing flow throughout the tropical troposphere from Africa to the Indian Ocean was characterized by weak, recirculating easterlies, which allowed most of the pollution to remain over the tropical Indian Ocean through November. Transport to the UT via deep convection mixed the pollution throughout the troposphere over the tropical Indian Ocean. We find similar concentrations, distributions, and transport pathways in the simulation presented here, so we do not repeat a comparison with the observations presented in Duncan et al. (2003b).

Duncan et al. (2003b) could not determine if the pollution transported to the LS was realistic; transport in their CTM was driven by assimilated meteorology, which was known to cause excessive stratosphere-troposphere exchange (STE), a common problem of assimilated fields (e.g. Douglass et al., 2003; Schoeberl et al., 2003). Here, we use GEOS-4GCM meteorological fields (1997 SSTs), which have reasonable STE (Olsen et al., 2004), to drive transport in the Combo CTM. As the ENSO phenomenon is largely driven by SSTs, our simulation captures the major meteorological features associated with this historic El Niño. For instance, the locations of tropical precipitation agree reasonably well with the distributions from the Global Precipitation Climatology Project (GPCP) for August through November 1997 (Adler et al., 2003). The GEOS-4-GCM and observed precipitation are higher than climatology (1979-1999) over the central/eastern Pacific and western Indian Oceans, and lower over the Maritime continent and eastern Indian Ocean, which are characteristics of the El Niño phase (Dai and Wigley, 2000). The Walker Circulation is historically weak during the El Niño phase, so it is possible that pollution from widespread wildfires in Indonesia (e.g. 1982-1983, 1991, 1994, 1997-1998) follow similar transport pathways as in 1997.

In Sects. 4.1-4.2, we present the results of two simulations, with and without the Indonesian wildfire emissions. We refer to the difference in trace gas concentrations between the two runs as perturbations caused by the wildfires. We use the following definitions for the TTL, LS, and LMS in our discussion. The TTL is the region below the tropopause ( $380 \mathrm{~K}$ potential temperature in the tropics), but at pressures $<150 \mathrm{mb}$. The LS is the region above $380 \mathrm{~K}$ potential temperature, but below $60 \mathrm{mb}$. The LMS is the region above the tropopause, but below $380 \mathrm{~K}$ potential temperature. The tropopause is defined by Ertel's potential vorticity $\left(<3.5 \times 10^{-6} \mathrm{~K} \mathrm{~m}^{2} \mathrm{~kg}^{-1} \mathrm{~s}^{-1}\right)$ or potential temperature $(<380 \mathrm{~K})$, whichever gives the higher pressure. We consider all latitudes in our definitions, though the perturbations 

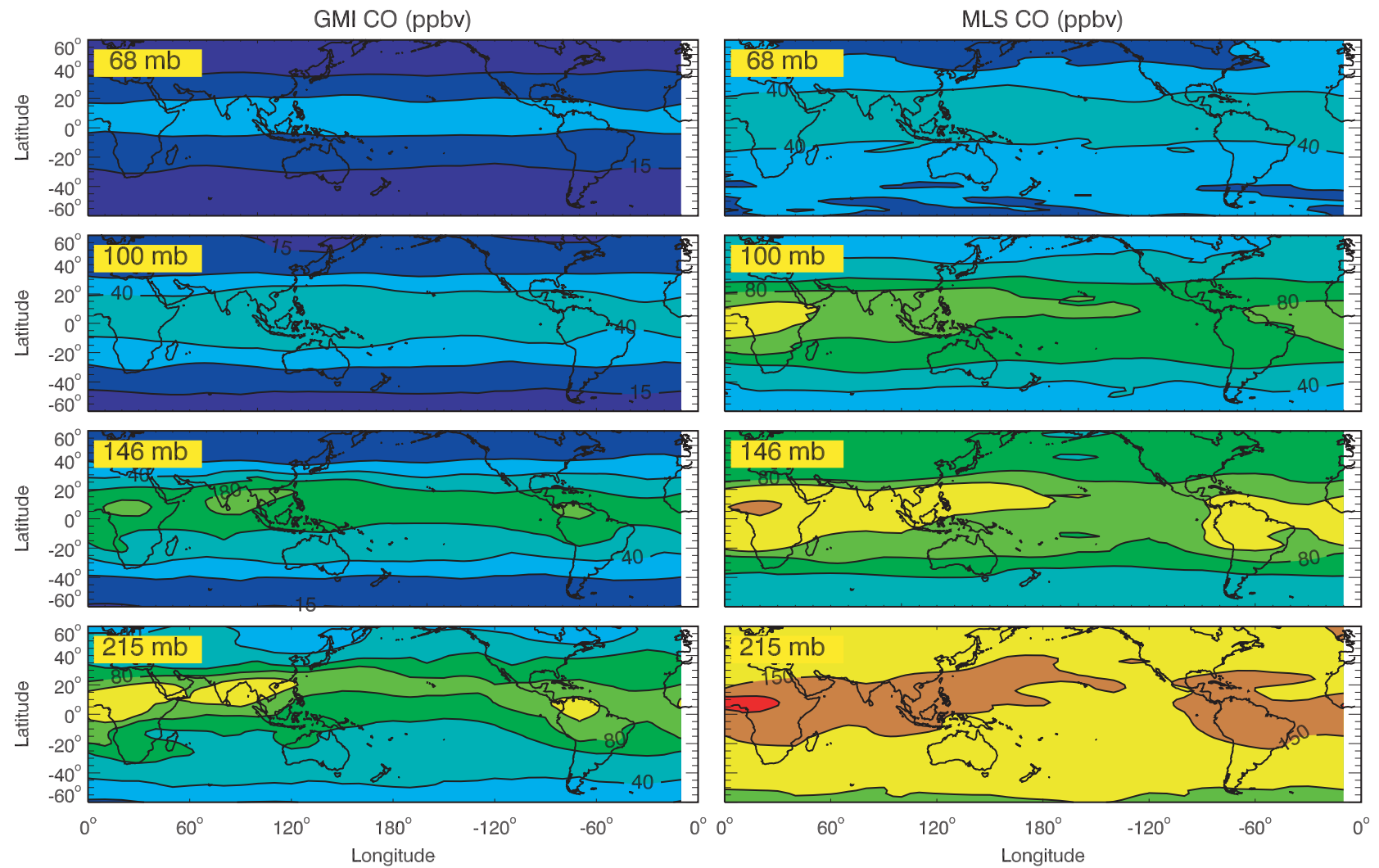

Fig. 4. A comparison of simulated CO in March as a mean for 1994-1998 with MLS CO for March 2005 at four pressure levels. The contours are $10,15,25,40,60,80,100,150$, and 200 ppbv.
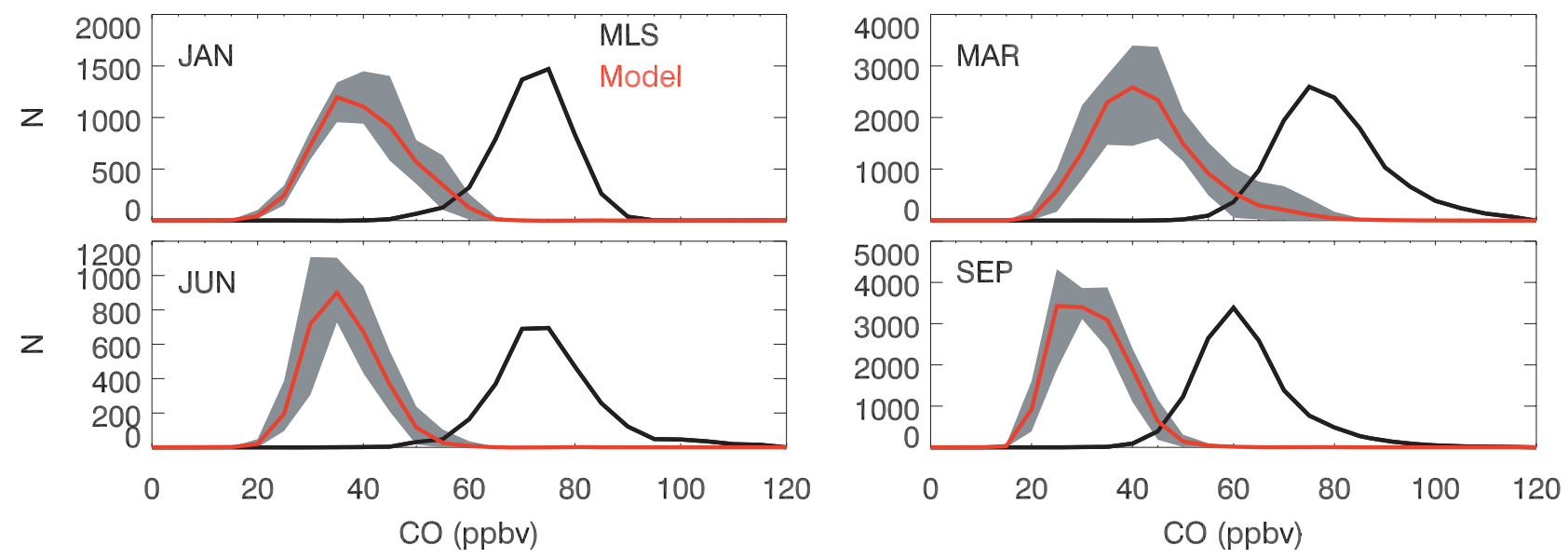

Fig. 5. A comparison of the MLS CO (black) for March 2005 and the mean simulated CO (red) for March $1994-1998$ from $20^{\circ} \mathrm{N}-20^{\circ} \mathrm{S}$. The gray shaded area shows the range of the simulation during 1994-1998.

are generally found between $60^{\circ} \mathrm{S}$ and $60^{\circ} \mathrm{N}$. We calculate monthly-averages from daily-averages as the tropopause can vary significantly, especially in the subtropics.

\subsection{Transport pathways within the TTL and LS}

The cross-tropopause transport of the wildfire's pollution occurs by slow ascent in the TTL to the LS, especially over the Indian Ocean, and quasi-horizontal exchange to the LMS, 


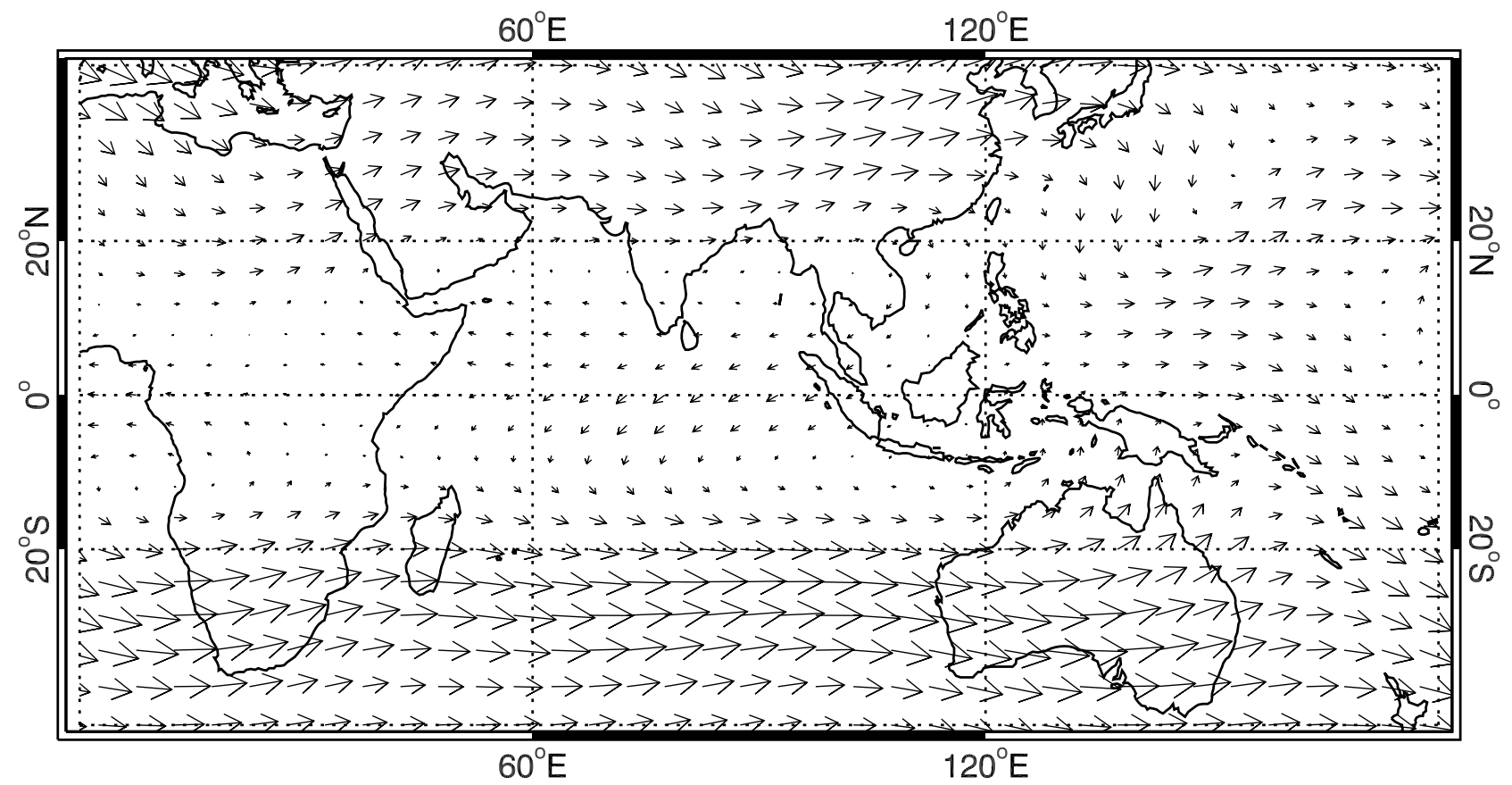

Fig. 6. GEOS-4-GCM winds (m/s) at $200 \mathrm{mb}$ for October 1997.

especially in the SH. We find that the two TST pathways are both important in our simulation with the LMS and tropical LS being significantly perturbed by biomass burning pollution. We do not attempt to quantify the relative importance of each pathway in our study as CO is not an inert tracer (see Sect. 4.2). However, Levine et al. (2007) found that $\sim 95 \%$ of an inert tracer released during January 2001 at the base of the TTL entered the LMS.

\subsubsection{Quasi-horizontal exchange}

In general, the maximum extent of the convective upward mass flux in our simulation is $350-360 \mathrm{~K}$. While advective flow in the tropical UT is characterized by weak, recirculating easterlies, westerly flow in the subtropical jets $\left(>20^{\circ} \mathrm{N}\right.$ and $>20^{\circ} \mathrm{S}$ ) is relatively strong, especially the southern jet as it is seasonally stronger (Fig. 6). Flow throughout the TTL is similar to that shown in Fig. 6.

Figure 7 shows the monthly-averaged CO perturbation (\%) at $200 \mathrm{mb}$ for August through November. The bulk of the CO remains over the tropical Indian Ocean in all four months, where the perturbation is $>100 \%$ over much of the region. In August and September, the pollution is transported by the tropical easterly jet, which weakens in October and November as the Asian monsoon circulation breaks down. The figure shows that pollution is peeled away by the subtropical jets, especially the southern jet, from the main plume over the Indian Ocean in September and October, rapidly circling the globe (Figs. 7c-d).
The importance of TST to the LMS is seen in Fig. 8, which shows the CO perturbation (\%) in October for a vertical slice at the International Date Line. (The monthlyaveraged perturbation and the monthly-averaged location of the tropopause are shown in this figure for illustrative purposes only. They are not sufficient to identify the occurrence of TST to the LMS as the location of the subtropical tropopause can vary substantially within a month.) The perturbation is near $100 \%$ in the southern subtropics and $>50 \%$ in the northern subtropics. The CO moves into the LMS via quasi-horizontal exchange, increasing $\mathrm{CO}$ by $25-100 \%$. The mass perturbation of the SH LMS peaks in November at $35 \%$, remaining $>10 \%$ through March (Fig. 9). In the $\mathrm{NH}$ LMS, the peak occurs in October at $25 \%$, remaining $>15 \%$ through March. The perturbation lingers in the $\mathrm{NH}$ because $\mathrm{OH}$ is seasonally low during winter.

\subsubsection{Slow ascent in the TTL}

Figure 10a shows the $\mathrm{CO}$ perturbation in November near the tropical tropopause. The greatest perturbations $(>100 \%)$ are over Africa, the Indian Ocean, and the region of the southern subtropics. Figure 10b shows the CO perturbations in the LS. The perturbations closely resemble those at the tropopause, first appearing over subtropical Asia, tropical Africa and the entire southern tropics in September and October. The maximum perturbations ( $\sim 30 \mathrm{ppbv}$ ) occur in November over Africa and the tropical Indian Ocean, a region of preferential TST (Fueglistaler et al., 2004). At $60 \mathrm{mb}$ (not shown), the CO perturbation ( $\sim 5 \%$ or $1-2 \mathrm{ppbv})$ first appears over the 


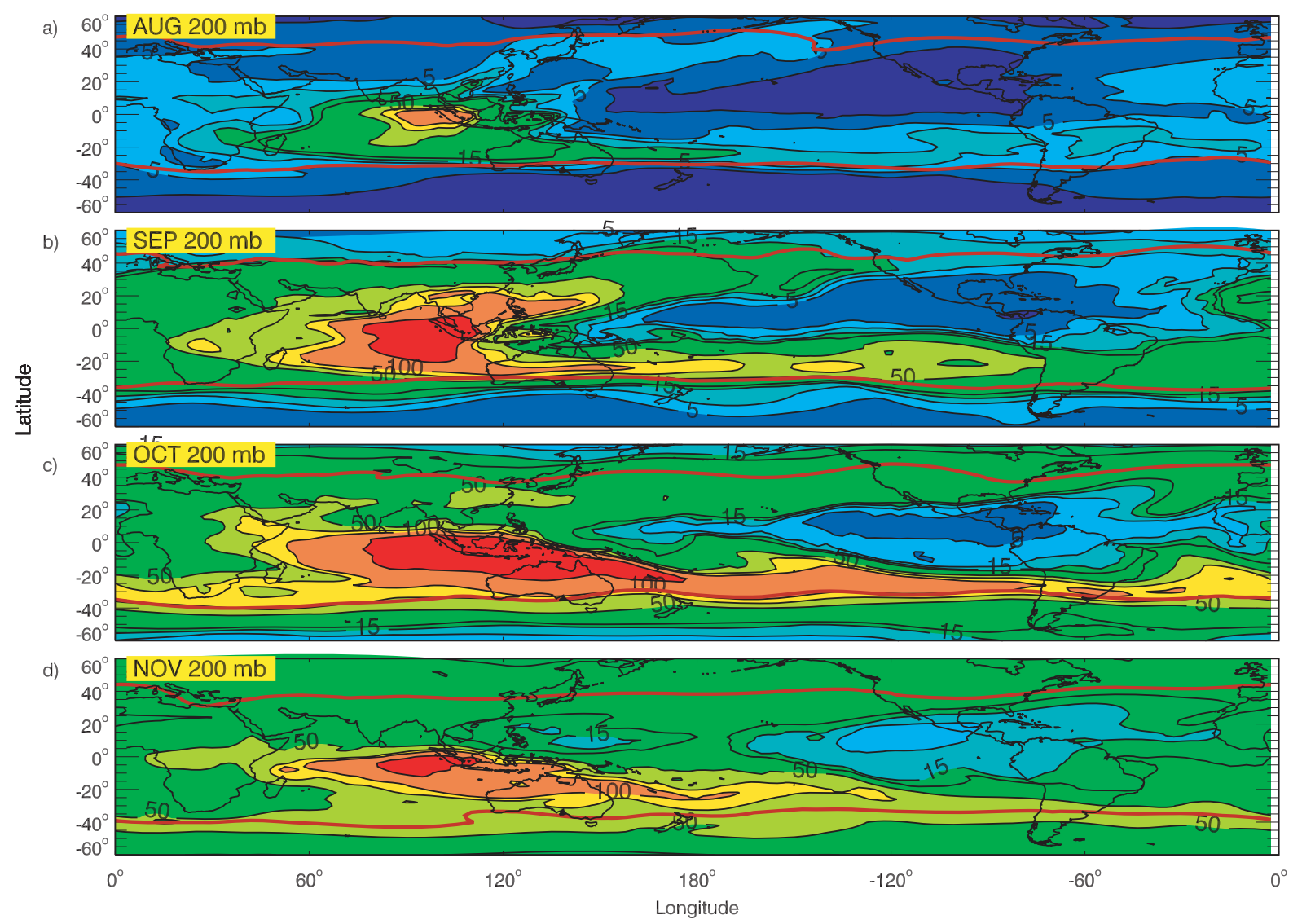

Fig. 7. The monthly-averaged CO perturbation (\%) for (a) August, (b) September, (c) October, and (d) November 1997 caused by the Indonesian fires at $200 \mathrm{mb}$. The monthly-averaged tropopause (red line) is defined by Ertel's potential vorticity $\left(<3.5 \times 10^{-6} \mathrm{~K} \mathrm{~m}^{2} \mathrm{~kg}^{-1} \mathrm{~s}^{-1}\right.$ or potential temperature $(<380 \mathrm{~K})$, whichever gives the higher pressure. The contours are $1,5,10,15,20,50,75,100$, and $200 \%$.

tropical Atlantic and S. America in October; at this altitude, the total simulated CO is only 10-15 ppbv. By December, the perturbation is rather well-mixed, 10-25\% (1-3 ppbv) and lingers through March. The mass perturbation of the TTL peaks in October (55\%), while the peak in the LS occurs later in December (15\%) (Fig. 9).

The main entry point of the Indonesian pollution to the TTL does not occur over the Warm Pool. A number of factors conspire to minimize the impact of the pollution over the Pacific. First, much of the pollution disperses in the subtropical jets, which lay to the north and south of the Warm Pool. Second, most CO is transported to the Indian Ocean because of a weak Walker Circulation and remains there because of weak and recirculating winds, as discussed above. Third, strong convection off the equatorial Pacific coast of Central America, which is associated with the strong El Niño, pumps air not significantly impacted by the wildfires from the lower troposphere to the UT (Fig. 7).

\subsection{Impact on trace gases in the TTL and LS}

As mentioned above, $\mathrm{CO}$ is not an inert tracer. For instance, the lifetime generally increases with altitude from the tropical UT ( $\sim 40-70$ days) to LS ( $\sim 50-80$ days). There are two issues that impact the lifetime of $\mathrm{CO}$, and consequently that of $\mathrm{OH}$, during our study period. First, the lifetime is longer in the SH subtropical UT/LS early in the study period as $\mathrm{OH}$ is low, but decreases through austral spring as solar radiation increases. By November, the lifetimes near the tropical tropopause and the SH subtropical UT/LS are similar, 40-70 days; the lifetimes in the NH subtropical UT/LS are 50-90 days at this time. Second, the CO lifetime grows (as compared to the unperturbed case) because $\mathrm{CO}$ accumulates during the long burning event. That is, the concentration of $\mathrm{CO}$ affects its own loss rate. We find that the $\mathrm{CO}$ lifetime increases by $5-10$ days in the UT/LS for several months because of pollution from the Indonesian fires.

$\mathrm{OH}$ is the primary sink for $\mathrm{CO}$, so its zonal mean perturbation (Fig. 11a) closely follows that of the CO perturbation. In October, the OH perturbation in the TTL is negative $(5-20 \%)$, especially in the subtropical UT. When only 


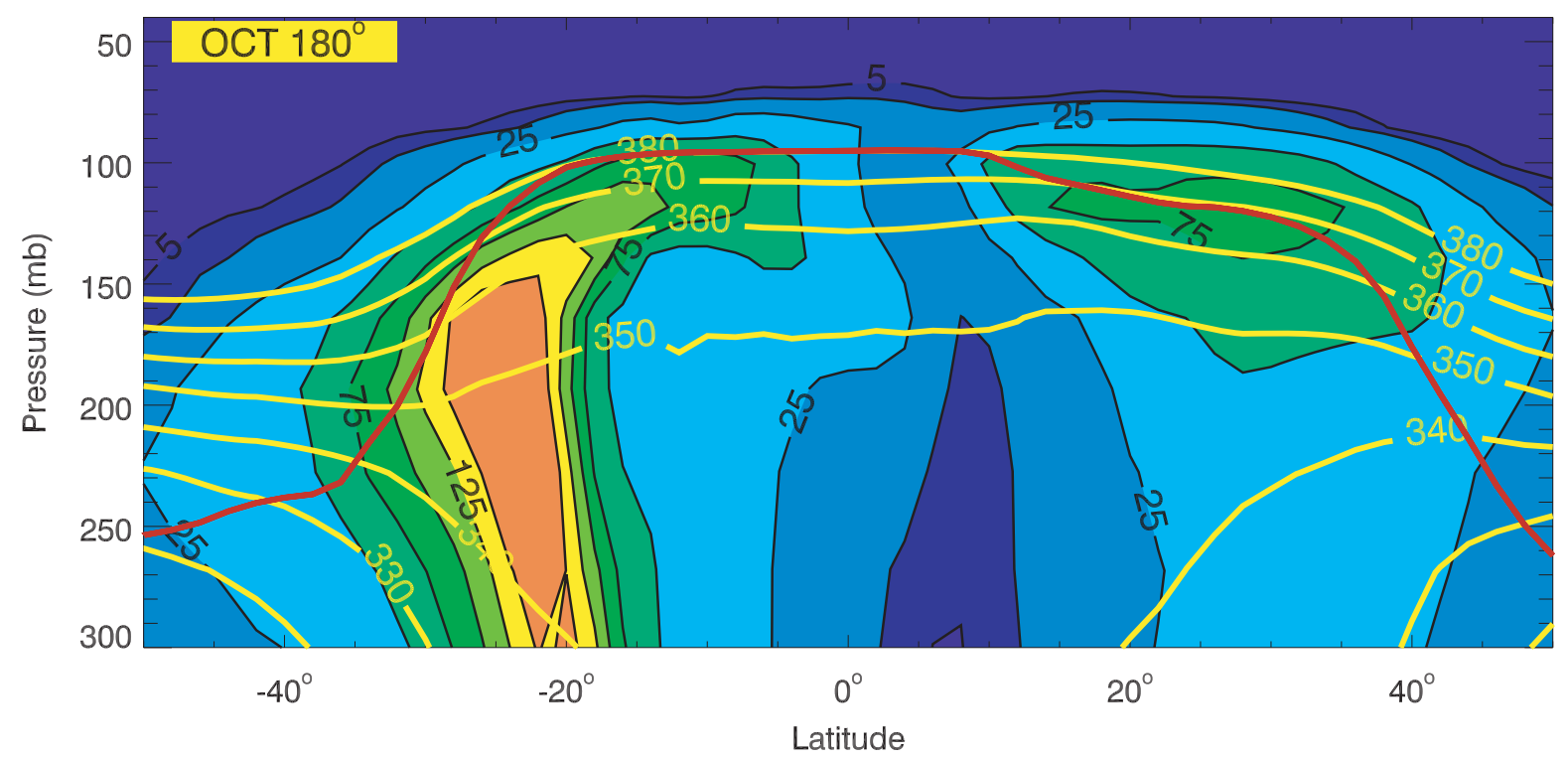

Fig. 8. The monthly-averaged CO perturbation $(\%)$ at $180^{\circ}$ longitude in October 1997 caused by the Indonesian fires. Potential temperatures $(\mathrm{K})$ are shown as yellow lines. The monthly-averaged tropopause is shown as a red line. The contours are 5, 10, 25, 50, 75, 100, 125, and $150 \%$.

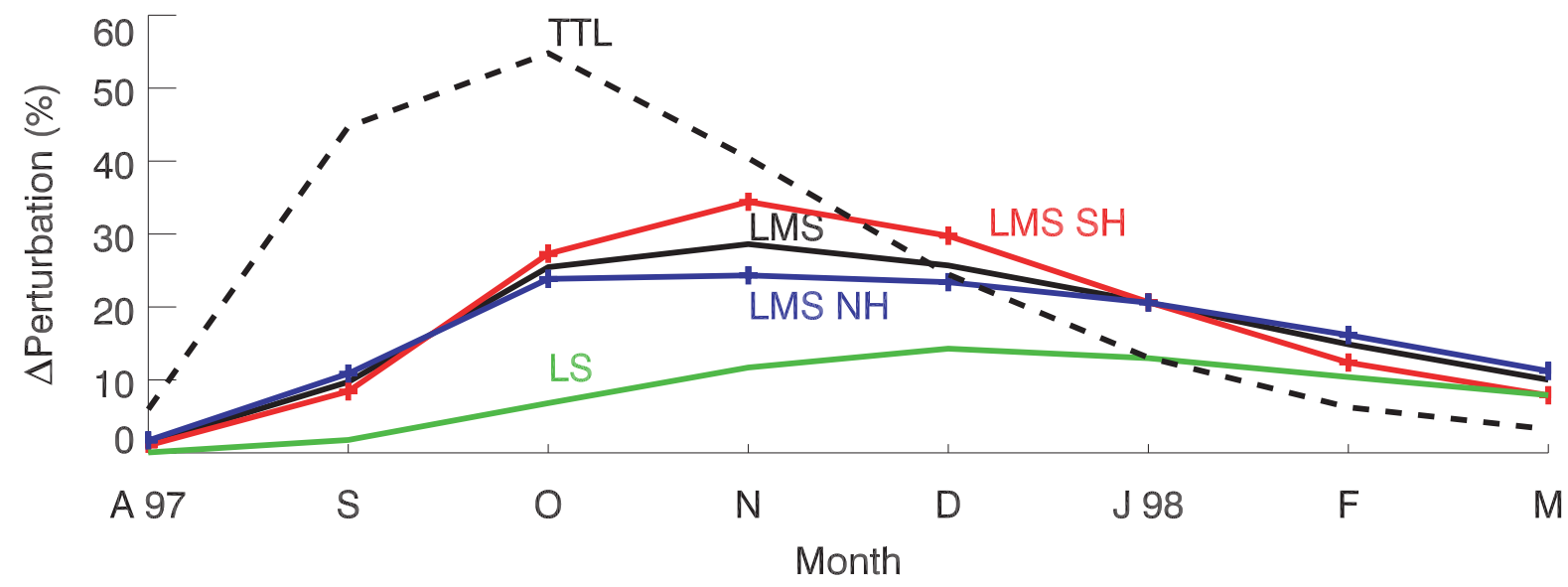

Fig. 9. The monthly-averaged mass perturbation of CO (\%) in the TTL (dashes), LMS (solid), and LS (green). The portions of the LMS perturbation in the $\mathrm{NH}$ (blue crosses) and SH (red crosses) are shown. The perturbation of each region is relative to the mass of that region. See Sect. 4 for the definitions of each region.

the Indian Ocean region is considered, the $\mathrm{OH}$ in the entire TTL is lower by $>15 \%$ (Fig. 11b). While a $15 \%$ decrease in $\mathrm{OH}$ over several months in the TTL is significant by itself, it becomes even more important when one considers that air in the TTL typically resides there for several weeks before crossing the tropopause (Fueglislater et al., 2004). Therefore, a trace gas that has a primary sink by reaction with $\mathrm{OH}$ will have a longer lifetime, allowing more of it to cross the tropopause.

The zonal mean ozone perturbation is shown in Fig. 11c. It is $>15 \%$ in much of the TTL from September to Novem- ber and $>25 \%(>15 \mathrm{ppbv})$ in October. When only the Indian Ocean is considered (Fig. 11d), the highest perturbation ( $>15 \mathrm{ppbv}$ ) in the TTL is along the equator and the southern subtropics, though the perturbation is $>10 \mathrm{ppbv}$ over the entire TTL. A change in ozone in the TTL may impact the LZH, though this effect is not expected to be large for ozone (Gettelman et al., 2004). Nevertheless, this experiment shows that 1) biomass burning pollution can significantly elevate ozone in the entire TTL for many months, presumably impacting the dynamics there, and 2) ozone in both the LS and LMS can be impacted by a large biomass burning event. 


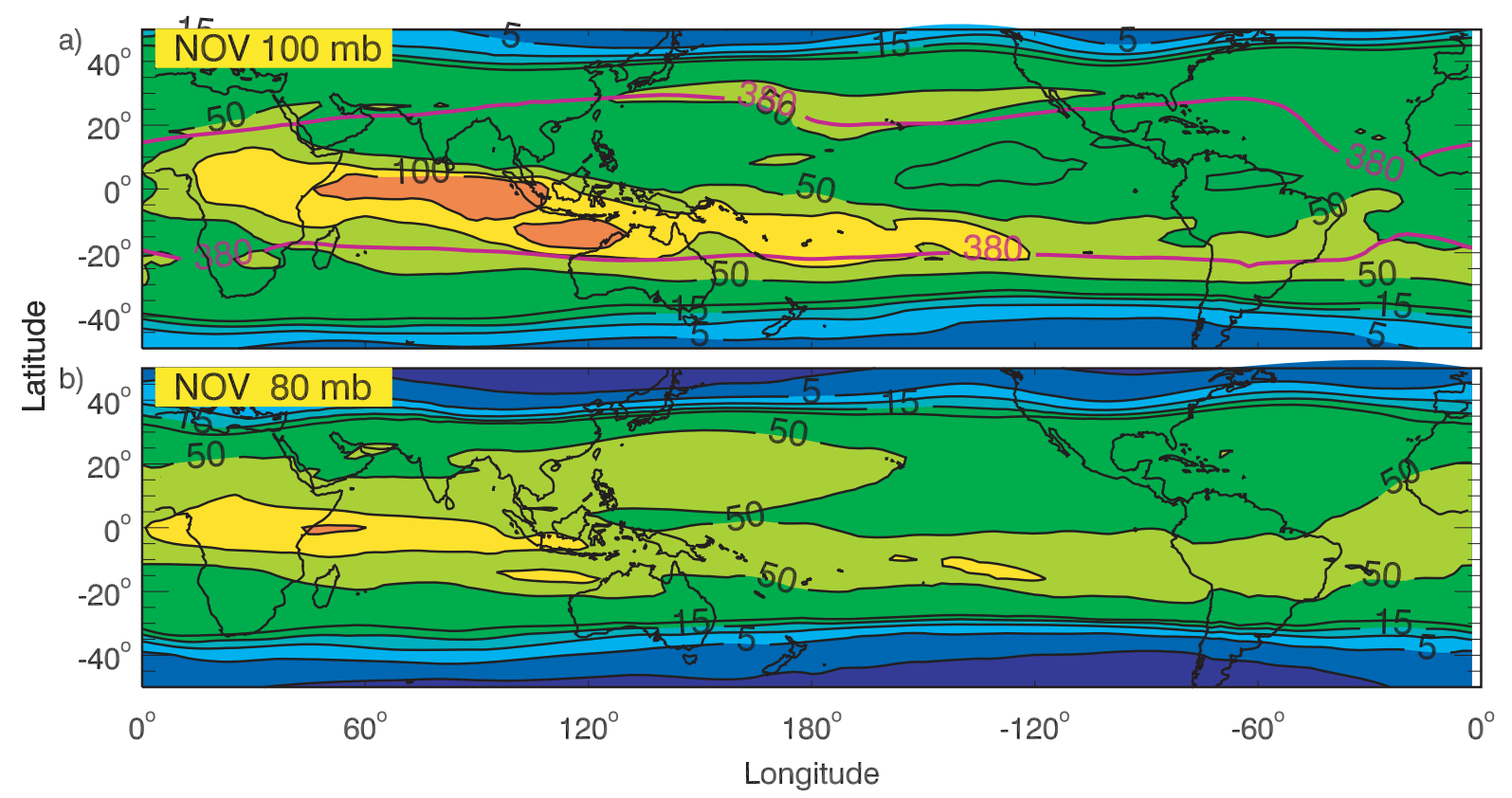

Fig. 10. The CO perturbation (\%) in November 1997 caused by the Indonesian fires (a) near the tropopause and (b) in the LS. The $380 \mathrm{~K}$ potential temperature (pink line) shows the approximate location of the monthly-averaged tropopause. The contours are 1, 5, 10, 15, 20, 50, 75 , and $100 \%$.

\section{Sources of variation in the UT/LS composition}

In Sect. 4, we used an extreme biomass burning event, the 1997 Indonesian wildfires, to identify two main pathways for the pollution to enter the stratosphere: i. slow ascent in the TTL to the LS and ii. quasi-horizontal exchange to the LMS. We find these two pathways are also important for more modest burning events as shown here. In Sect. 5, our goal is to understand how temporal and spatial variations in pollutant sources and dynamics impact the composition of the UT/LS. We examine the seasonal transport of biomass burning pollution to the UT/LS for a typical year, mid-1994 to mid-1995, to understand how usual variations in the timing and locations of burning contribute to $\mathrm{CO}$ perturbations in the UT/LS. We also investigate how the interannual variability of dynamics, including convection, affects transport of pollutants to/within the UT/LS. We use the same definitions of the TTL, LS, and LMS as in Sect. 4.

\subsection{TST of regional biomass burning pollution}

We performed five simulations. The base simulation is from mid-1994 to mid-1995 with climatological biomass burning sources. In the remaining simulations, we turned off sequentially the biomass burning emissions from four source regions: Africa south of the equator $(86 \mathrm{Tg} \mathrm{CO} / \mathrm{y})$, Africa north of the equator ( $87 \mathrm{Tg} \mathrm{CO} / \mathrm{y})$, South America south of the equator (60 Tg CO/y), and Southeast Asia (82 Tg CO/y). Figure 12 shows the seasonal variation of biomass burning by region from $30^{\circ} \mathrm{S}-30^{\circ} \mathrm{N}$. In all five simulations, we include the climatological emissions from Indonesia (Fig. 12); we do not assess the impact for this region as burning varies dramatically from year-to-year due to variations in the ENSO. For instance, burning during a La Niña is often 3-5 times less than during an El Niño (Duncan et al., 2003a).

\subsubsection{Southern hemisphere burning season}

South America, southern Africa, and the tropical southern Atlantic Ocean experience widespread pollution during the SH burning season (Fishman et al., 1991; Thompson et al., 1996; Chatfield et al., 1998). Burning occurs in southern Africa typically from May to November and from August to November in South America (Fig. 12). The transport pathways from the two regions allow their plumes to intermingle. They can be treated as one plume for the purpose of this experiment.

The large biomass burning plume lies generally south of tropical easterlies and north of SH subtropical westerlies. Figure 13a shows that tropical easterlies play the dominant role, transporting much of the pollution to the Pacific Ocean. A broad area of convection extends from western Africa, across South America, and to the central Pacific, which lofts the pollution to the UT (Figs. 13b-c). By October, this pollution is being transported by the southern subtropical jet (Fig. 13c). Figure 13a also shows a less important pathway, the transport of surface pollution in the subtropical westerlies to the Indian Ocean; this pollution typically is not lofted to 


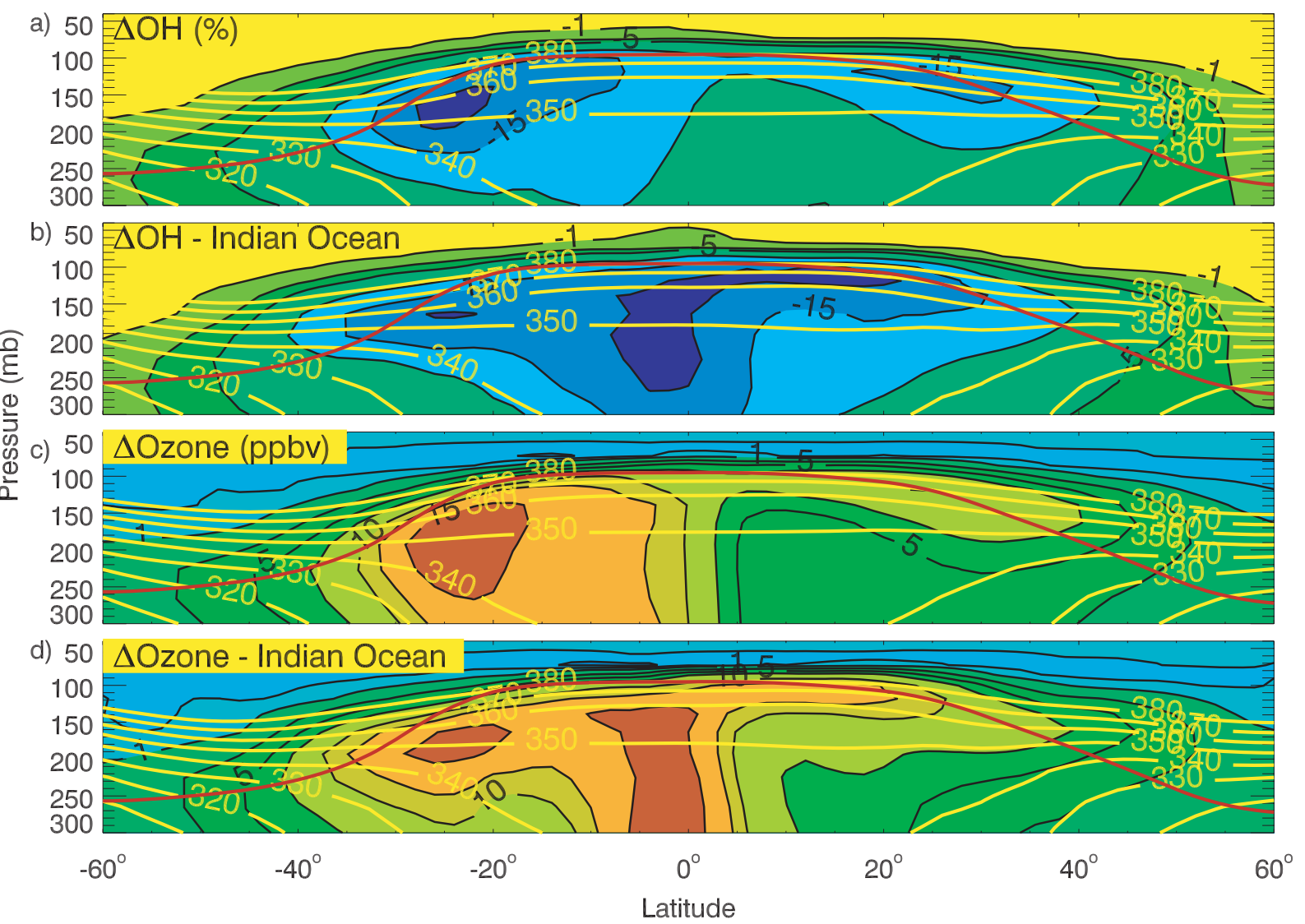

Fig. 11. (a) The monthly-averaged $\mathrm{OH}$ perturbation $(\%)$ as a zonal mean for October 1997. (b) Same as (a), except for the Indian Ocean region only. (c) Same as (a), except for the ozone perturbation (ppbv). (d) Same as (c), except for the Indian Ocean region only. Potential temperatures $(\mathrm{K})$ are shown as yellow lines. The monthly-averaged tropopause is represented by a red line. The contours for (a) and (b) are $-1,-3,-5,-10,-15$, and $-20 \%$ and for (c) and (d) are 1, 3, 5, 7, 10, 12, and 15 ppbv.

the UT as convection in the subtropics is not frequent.

Unlike the Indonesian pollution, ascent over the Warm Pool plays a role for pollution from South America and southern Africa (e.g. September in Fig. 13b). The pollution is first evident at the tropical tropopause in June over the Warm Pool and is $>5 \%$ over much of the tropics from September through December (Fig. 13d for October). By November, the perturbation $(\sim 10-15 \%)$ becomes rather uniform. The pollution reaches the LS (not shown) in August and September along the equator from the central Pacific westward to Africa, though the perturbation is only $1-5 \%$. It is widespread $(>10 \%)$ from October through December, and $>15 \%$ over central Africa in November. It reaches $60 \mathrm{mb}$ by December, though it is generally $\sim 1-3 \%$ with the highest perturbation over the equatorial Pacific.

\subsubsection{Northern hemisphere burning season}

Northern Africa. The burning season in northern Africa occurs mainly from November through March (Fig. 12). Much of the pollution near the surface moves with the tropical easterlies, polluting the entire tropical Atlantic and Pacific
Oceans by February and March (not shown). A minor pathway to the western tropical Indian Ocean occurs during most of the burning season. One would expect the impact on $\mathrm{CO}$ in the LS to be enhanced by seasonally high TST, as burning peaks in January. However, this is not the case. Although biomass burning emissions are high in January there is little deep convection to transport it to the UT. The perturbation in the UT peaks in March (Fig. 14a) and April when seasonal convection in central Africa becomes important as the ITCZ advances northward, closer to the burning regions.

The perturbation near the tropical tropopause peaks from March to May (April in Fig. 14b), where it is $>5 \%$ over the entire tropical tropopause region. However, it is first evident in January, when the highest values are 3-5\% over Indonesia, the tropical Pacific, and South America. In the LS, the pollution first appears in January over the Warm Pool, and in February, it is $>5 \%$ over two regions of deep convection, the Warm Pool and off the Pacific coast of Central America (February in Fig. 14c). It remains high (5-10\%) from March through May over the entire tropics. 
Southeast Asia. While the burning seasons occur over several months for the two African regions and South America, approximately $50 \%$ of the biomass burned in Southeast Asia occurs in March (Fig. 12). Pollution is transported by the prevailing surface winds to the Indian and Pacific Oceans, where it is lofted to the UT by convection over the Bay of Bengal and the South China Sea. Figure 15a shows that the $\mathrm{CO}$ perturbation at $200 \mathrm{mb}$ is $>25 \%$ over the Bay of Bengal and Southeast Asia in March. This pollution is transported rapidly by the northern subtropical jet across the Pacific Ocean, circumnavigating the globe by April; the perturbation is $5-10 \%$ over much of the NH tropical and subtropical Indian and Pacific Oceans. A minor amount of the pollution is caught in the southern subtropical jet (Fig. 15a). The pollution first appears near the tropopause over the Warm Pool in February $(\sim 1 \%)$ and over large regions of the tropics by March and April (Fig. 15b). The pollution is high in April $(>25 \%)$ over the Arabian Sea to the South China Sea and is $>10 \%$ over most of the NH tropics and subtropics.

\subsection{Contribution of sources}

In Sect. 5.1, we showed that biomass burning pollution from various regions influences $\mathrm{CO}$ in the UT/LS. We show here that a combination of seasonal variations in other sources of $\mathrm{CO}$, in addition to biomass burning, and the seasonal cycle in mean ascent associated with the Brewer-Dobson circulation shape the seasonal oscillation in the UT/LS composition. We present the results of two simulations, in which we separate the component of the oscillation due to variations in transport (i.e. convection and slow ascent from the TTL to the LS) from the variations in the individual contributions of each CO source. The first is a "tagged CO" simulation in which different sources of $\mathrm{CO}$ are carried as separate tracers (e.g. biomass burning CO from Indonesia, fossil fuel CO from eastern Asia, etc.). We use the same emissions as in the base simulation presented in Sect. 5.1. We also use monthlyaverage $\mathrm{OH}$ from the base simulation to compute the source of CO from methane oxidation and the loss of CO. The sum of the $\mathrm{CO}$ tracers approximates $\mathrm{CO}$ in the base simulation to within a few percent in the UT/LS. The tagged CO method is described in detail in Duncan et al. (2007). The second is a uniform tracer simulation, in which we emit $\mathrm{CO}$ homogeneously over the earth's surface ( $2400 \mathrm{Tg} \mathrm{CO} / \mathrm{yr}$ ) and assume a uniform 25 day lifetime. Consequently, the uniform tracer is not directly comparable to $\mathrm{CO}$ from the base simulation, but it is decoupled from the seasonal variation in sources, leaving only the variation due to transport.

\subsubsection{UT/LS}

If biomass burning were the only cause of variation in the composition, one would expect a semi-annual oscillation in mean CO in the UT/LS: two maxima (during the NH and SH burning seasons) and two minima (the periods between them)

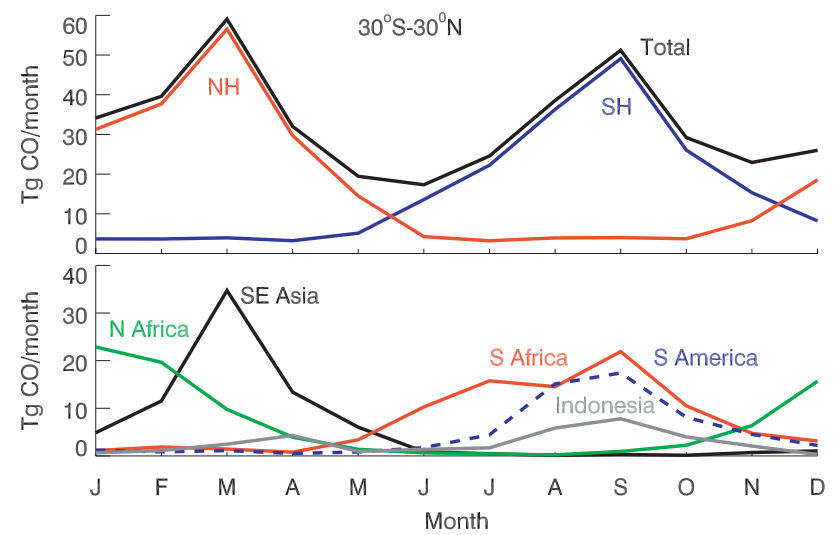

Fig. 12. Direct climatological biomass burning emissions (Tg $\mathrm{CO} /$ month) from $30^{\circ} \mathrm{S}-30^{\circ} \mathrm{N}$ (top panel) and by region (bottom panel). For clarity, the line for South America is dashed blue.

(Fig. 12). A semi-annual oscillation does occur below the TTL (not shown). However, a transition occurs in the TTL from this semi-annual oscillation to an annual oscillation in the LS. The top panels of Figs. 16-17 show the mean tropical CO from the base simulation (black line) with the annual average removed for the 1994-1995 burning season. In the TTL, a quasi-annual oscillation is evident; CO remains high during boreal winter, but not austral winter. This transition from a quasi-annual oscillation in the UT to an annual one in the LS is also seen in the MLS CO tape recorder (Fig. 1 of Schoeberl et al. (2006)).

Why is CO in both the TTL and LS high during boreal winter, but not summer? First, Rosenlof (1995) found that the ascent rate in the LS is higher in boreal winter than summer, which is consistent with our simulation; our uniform tracer simulation shows that more CO enters the UT/LS in boreal winter than summer (top panels of Figs. 16-17). Tagged CO from methane oxidation effectively provides a constant CO source in the TTL and thus, like the uniform tracer, behaves as a dynamical tracer here (bottom panels of Figs. 16-17). This is expected as methane is well-mixed in the troposphere and tropical $\mathrm{OH}$ is consistently high, so we treat it as a fixed boundary condition in all our simulations.

Second, the long-range transport of $\mathrm{CO}$ from fossil fuels emitted in the NH extra-tropics and subtropics increases the background concentration of the northern tropics by $\sim 20 \%$ in boreal winter/early spring (Duncan et al., 2007). (The time-scale of meridional transport is relatively long compared to the $\mathrm{CO}$ lifetime, except in winter when $\mathrm{OH}$ is low.) As this long-range transport occurs just before and during the $\mathrm{NH}$ burning season, tropospheric $\mathrm{CO}$ in the $\mathrm{NH}$ tropics reaches an annual maximum in late winter/early spring; Figs. 16-17 (bottom panels) show that the seasonal variations associated with $\mathrm{CO}$ from fossil fuels peak in boreal winter/spring when the ascent rate is seasonally high, thus enhancing the impact of this source on the composition in the LS. 


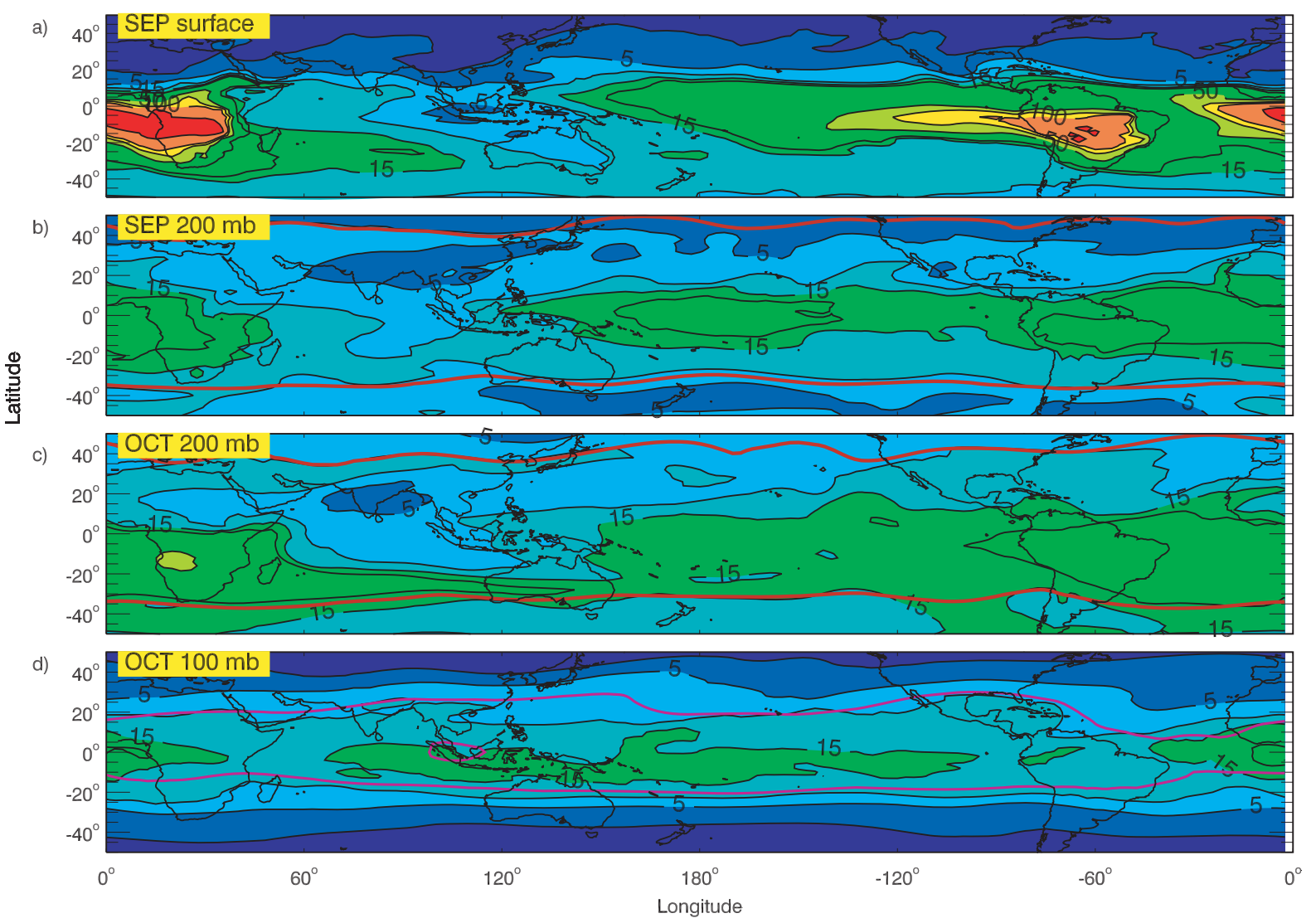

Fig. 13. The monthly-averaged CO perturbation (\%) for (a) September 1994 near the surface, (b) September at $200 \mathrm{mb}$, (c) October at $200 \mathrm{mb}$, and (d) October at $100 \mathrm{mb}$ caused by the biomass burning in southern Africa and South America. The monthly-averaged tropopause is represented by a red line or the $380 \mathrm{~K}$ potential temperature (pink line). The contours are 1, 5, 10, 15, 20, 50, 75, 100, and 200\%.

The minimum in $\mathrm{CO}$ occurs in boreal summer/early fall in the UT/LS when the ascent rate is seasonally low (top panels of Figs. 16-17) and $\mathrm{CO}$ in the northern tropics is at an annual minimum as the NH burden of $\mathrm{CO}$ is seasonally low (Duncan et al., 2007). The Asian summer monsoon is active, lofting surface pollution from India. (Indian emissions represent the largest source of $\mathrm{CO}$ from fossil fuel and biofuels year-round in the tropics.) However, in a simulation in which we removed Indian emissions (not shown), the Indian CO largely remains at latitudes $>15^{\circ} \mathrm{N}$, consistent with observations (Li et al., 2005; Kar et al., 2004), and does not significantly impact the TTL $\left(12^{\circ} \mathrm{N}-12^{\circ} \mathrm{S}\right)$.

Figures 16-17 (bottom panels) show that the relative contribution of each source to the seasonal oscillation in the TTL is different from the LS. There are two reasons for this. First, $\mathrm{CO}$ from methane oxidation is a $3-\mathrm{d}$ source, with year-round, in situ production in the UT, unlike near-surface emissions and other chemical sources (e.g. the oxidation of short-lived biogenic NMHC). Consequently, the seasonal oscillation attributed to near-surface sources is smaller in the LS than the TTL, but not for CO from methane oxidation. Second, the ascent rate from the TTL to the LS is seasonally high in bo- real winter and low in summer, so that $\mathrm{CO}$ from sources that maximize in the TTL in boreal winter has more impact on the composition of the LS than CO from sources that maximize in summer. For instance, $\mathrm{CO}$ from SH burning in austral spring arrives to the TTL when the ascent rate is seasonally low, while $\mathrm{CO}$ from $\mathrm{NH}$ burning in boreal spring arrives when the ascent rate is seasonally high. When ascent rates are convolved with the $\mathrm{CO}$ lifetime, the semi-annual oscillation of biomass burning CO seen in the TTL evolves to a quasi-annual oscillation in the LS during ascent.

\subsubsection{LMS}

Pollution transported to the LMS does not contribute to the tape recorder, though quasi-horizontal exchange is an important TST pathway as shown in Sects. 4 and 5.1. Figures 18ab are similar to Fig. 16, except for the LMS of each hemisphere. They show that the seasonal CO oscillations are similar in both hemispheres, but shifted by about six months. As in the TTL and LS, much, but not all, of the variation in the LMS is due to seasonal biomass burning. The seasonal maximum $\mathrm{CO}$ occurs in local spring during the burning season, 

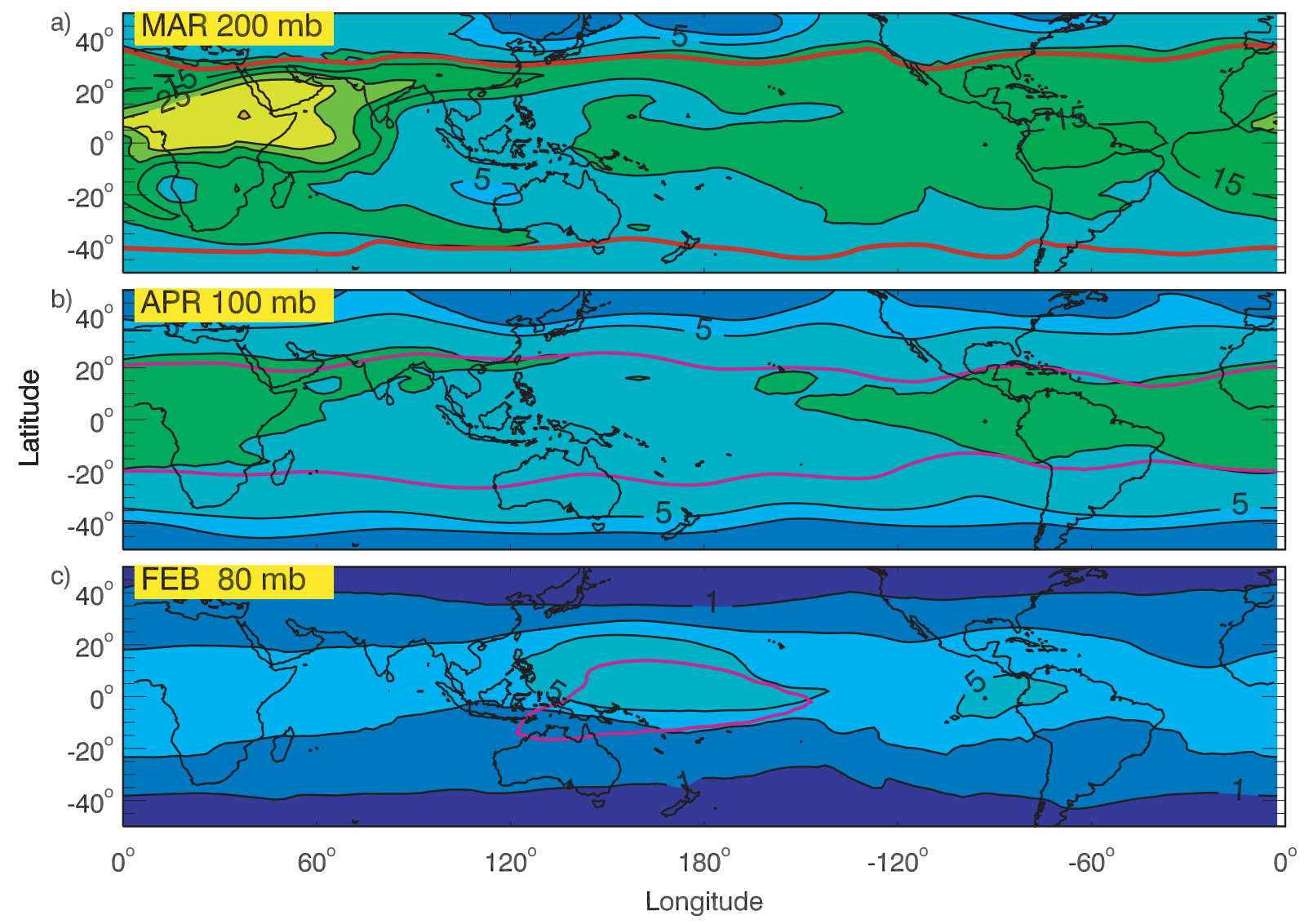

Fig. 14. The CO perturbation (\%) from biomass burning in northern Africa at (a) $200 \mathrm{mb}$ in March, (b) $100 \mathrm{mb}$, near the tropopause, in April, and (c) $80 \mathrm{mb}$ in February, from a simulation forced by 1995 SSTs. The monthly-averaged tropopause is represented by a red line or the $380 \mathrm{~K}$ potential temperature (pink line). The contours are $1,3,5,10,15,25$, and $50 \%$.

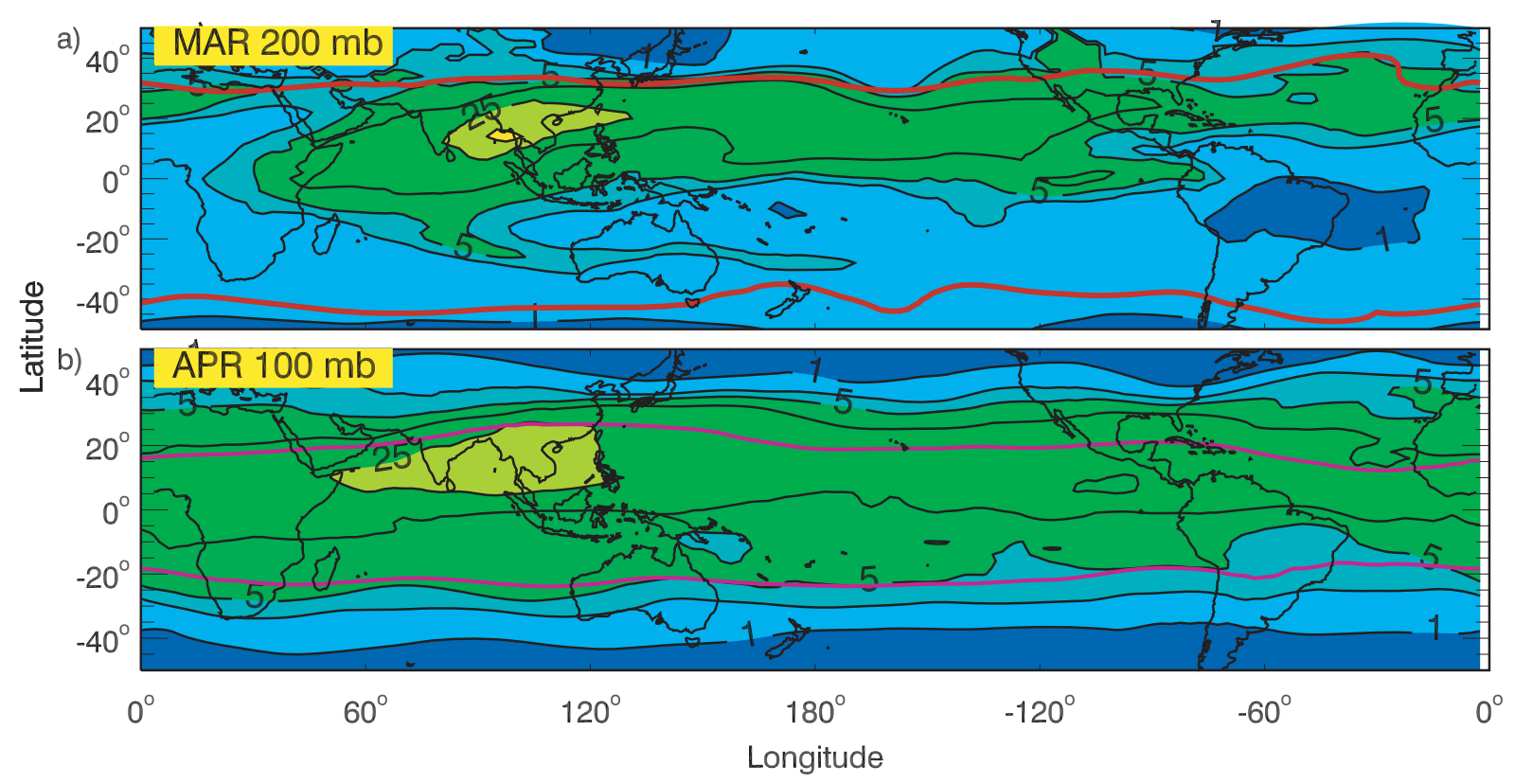

Fig. 15. Same as Fig. 14, except for Southeast Asia in 1994. 


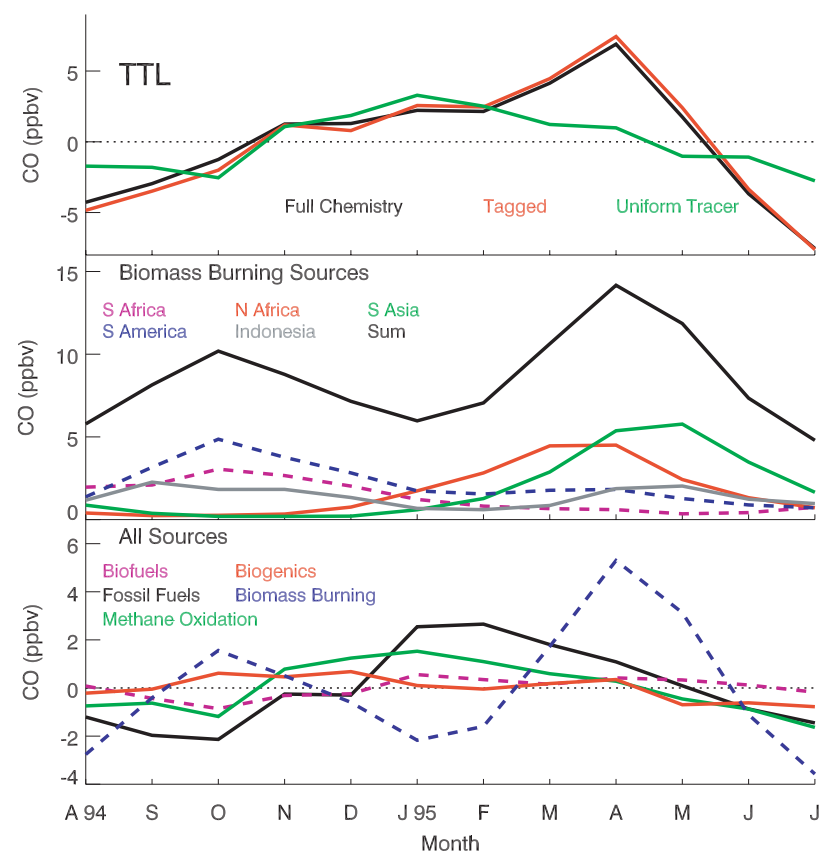

Fig. 16. (top) The monthly-mean $\mathrm{CO}$ (ppbv) with the annual mean removed in the TTL $\left(12^{\circ} \mathrm{N}-12^{\circ} \mathrm{S}\right)$ for three simulations: full chemistry, tagged $\mathrm{CO}$, and uniform tracer. The mean $\mathrm{CO}$ ranges from 44-58 ppbv for the 1994-1995 burning season. (middle) The tagged CO (ppbv) from biomass burning in South America, southern Africa, northern Africa, South Asia (i.e. Southeast Asia and India), and Indonesia - all climatological emissions. For clarity, the lines for southern Africa and South America are dashed. The sum of all five regions is also shown. (bottom) The tagged CO (ppbv) with the annual mean removed for biofuels, fossil fuels, methane oxidation, biogenics and biomass burning. For clarity, the lines for biomass burning and biofuels are dashed. The TTL is the region below the tropopause $(380 \mathrm{~K}$ potential temperature in the tropics), but at pressures $<150 \mathrm{mb}$.

a few months before the seasonal maximum in the uniform tracer in local summer. Seasonal biomass burning pollutes the LMS of both hemispheres, but more so in the hemisphere in which burning occurs.

The seasonal oscillation of the uniform tracer is weaker in the SH LMS than in the NH LMS because quasi-horizontal STE by summer monsoon circulations is weaker in the SH (Chen, 1995; Dunkerton, 1995). Information on the seasonal variation of TST via quasi-horizontal exchange is masked in Figs. 18ab as the mean seasonal oscillations shown are weighted toward higher latitudes where the LMS is vertically thicker. Since tropospheric air enters the LMS mainly in the subtropical UT, we show the uniform tracer at both lower latitudes $\left(<30^{\circ} \mathrm{N}\right)$, where tropospheric air is younger, and higher latitudes $\left(>30^{\circ} \mathrm{N}\right)$ of the NH LMS (bottom panel of Fig. 18a); the portion of the LMS at lower latitudes composes $9-16 \%$ of the total volume, depending on season.

The uniform tracer at lower latitudes shows a semi-annual

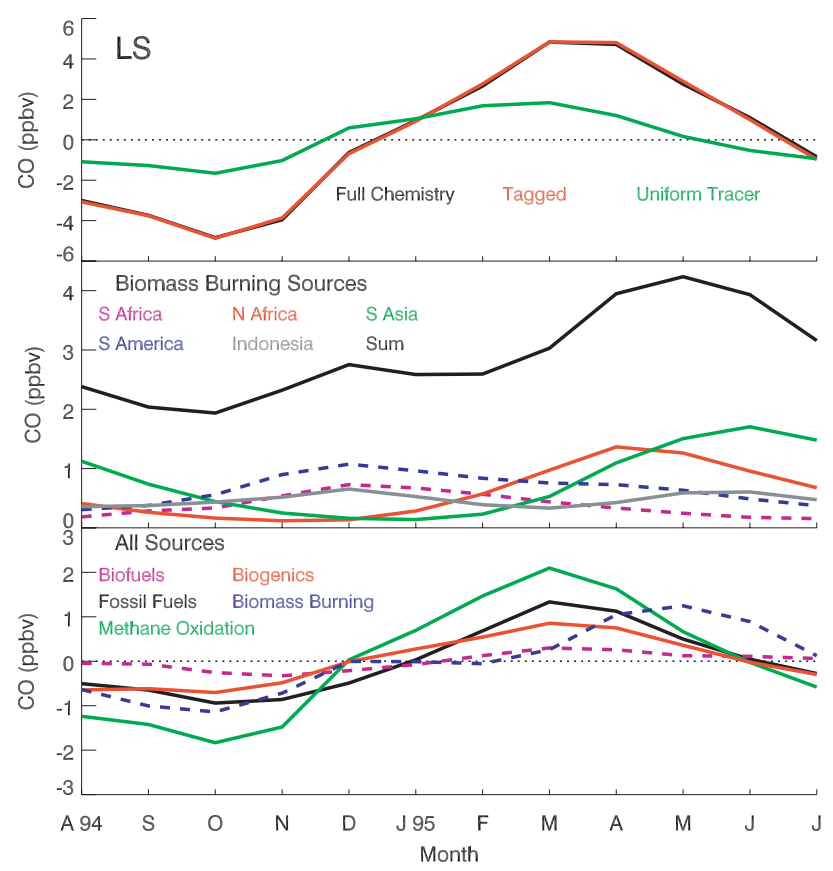

Fig. 17. The same as Fig. 16, except for the tropical LS (>380 K potential temperature and $>60 \mathrm{mb}$ ). The monthly-mean $\mathrm{CO}$ ranges from 16-25 ppbv.

oscillation, with maxima occurring during the boreal summer monsoons and when ascent rates in the tropics are high. This semi-annual oscillation shows that quasi-horizontal exchange can also occur in winter, not just during the summer monsoon season. However, the uniform tracer shows only an annual oscillation at higher latitudes that maximizes in summer. This occurs because the Asian monsoon provides a mechanism for mixing low-latitude air to the mid-latitudes (e.g. Dethof et al., 1999), which is not present at other times of the year.

\subsection{Interannual variability}

Interannual variability in the composition of the UT/LS can occur because of IAV 1) in CO sources, 2) in deep convection, and 3) in the ascent rate associated with the BrewerDobson circulation.

In Sect. 4, we discussed the extreme burning event in Indonesia in 1997, which was partially caused by an El Niñoinduced drought. The effects of El Niño are strongest typically during the SH burning season, although the ENSOinduced variability of precipitation is relatively weak yearround in southern Africa and South America. Consequently, the ENSO is not likely to be an important player in the IAV of biomass burning sources in these two regions. A similar argument can be made for burning in northern Africa and Southeast Asia, not including Indonesia. The ENSO can impact the transport of pollution from these regions to 


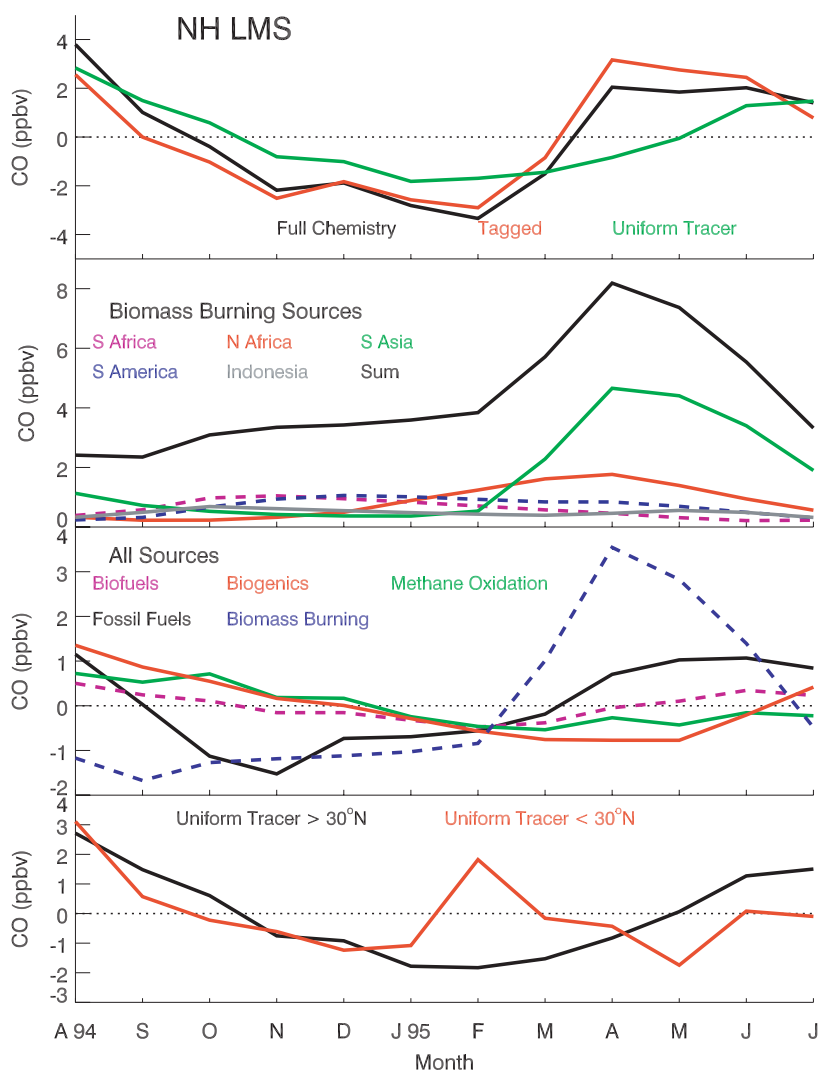

Fig. 18. (a) The same as Fig. 16, except for the NH LMS. The monthly-mean CO ranges from 30-38 ppbv. The bottom panel shows the monthly-mean $\mathrm{CO}$ (ppbv) for the uniform tracer with the annual mean removed for two zonal bands.

the UT/LS (e.g. via locations of convection) as discussed below. Historically, only burning during an El Niño is of consequence in Indonesia, Central America and Mexico.

Here, we discuss the dynamically-driven variability in the composition of the UT/LS for five years, 1994-1998. Our simulations capture the IAV in meteorology associated with the phases of the ENSO because the GEOS-4-GCM was forced with observed SSTs. We use climatological biomass burning emissions for all five years.

Figures 19ab show the mean CO in the TTL and LS for 1994-1998 with the 5-yr mean removed. Figure 19c shows the Oceanic Niño Index (ONI; degrees), where values $>0.5^{\circ} \mathrm{C}$ indicate $\mathrm{El}$ Niño conditions and $<-0.5^{\circ} \mathrm{C}$ indicate La Niña conditions. The El Niño phase occurred from April 1994 through March 1995 (i.e. the 1994-1995 burning season), though from April through September the phase was relatively weak, and from May 1997 through April 1998 (i.e. the 1997-1998 burning season); this was one of the strongest El Niño events on record. The La Niña phase occurred from October 1995 through March 1996 (i.e. the 1995-1996 burning season), though the entire phase was relatively weak. The other months, including the 1996-1997 burning season, were

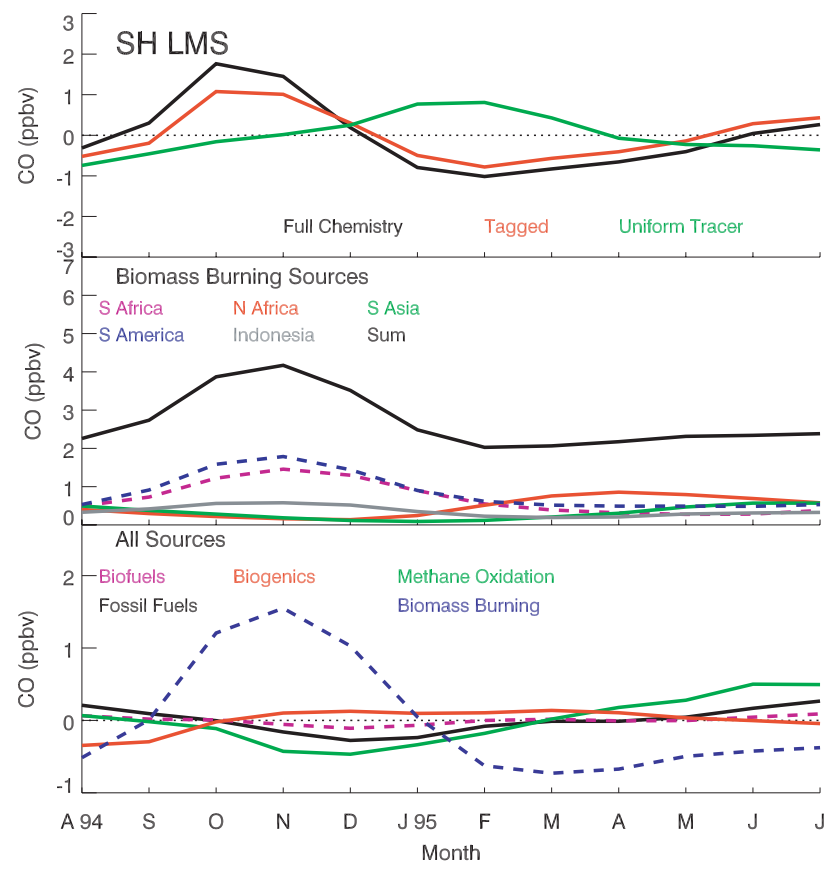

Fig. 18. (b) The same as Fig. 16, except for the Southern Hemisphere LMS. The monthly-mean CO ranges from 19-25 ppbv.

in the neutral phase $\left(0.5^{\circ} \mathrm{C}>\mathrm{ONI}>-0.5^{\circ} \mathrm{C}\right)$. The phases of ENSO influence the composition of the UT/LS. For instance, the minimum CO in the TTL occurs in July and August in 1995, 1996, and 1998, during neutral or La Niña conditions; the two years with the highest minimums occur in 1994 and 1997 during El Niño events (Fig. 19).

The meteorology of the abnormally strong El Niño of 1997-1998 enhances transport of CO to the UT mainly because of shifts in the locations of deep convection in relation to major sources. The convective updraft flux in the simulation during this time is about $10 \%$ higher as a zonal mean at $300 \mathrm{mb}$ than in the other years. However, deep convection off the Pacific coast of tropical South America is 23 times higher during this period as compared to the other years (Fig. 19d), which is characteristic of the El Niño phase (Dai and Wigley, 2000). Consequently, more CO from South American and African sources traveling in the tropical easterlies is lofted to the UT than in the other years. In our tagged CO simulation, CO from South American sources (i.e. fossil fuels, biofuels, biomass burning, and biogenics) are all elevated, sometimes by 2-3 times, in the last third of 1997 and first third of 1998 as compared to the other years (not shown). Biomass burning $\mathrm{CO}$ from southern Africa is elevated in late 1997 and from northern Africa in early 1998 during their respective burning seasons.

In fact, our simulations show that the IAV in the UT/LS composition due to shifts in the locations of deep convection is larger than that due to variations in the mean ascent rate and depth/frequency of convection. The uniform tracer 


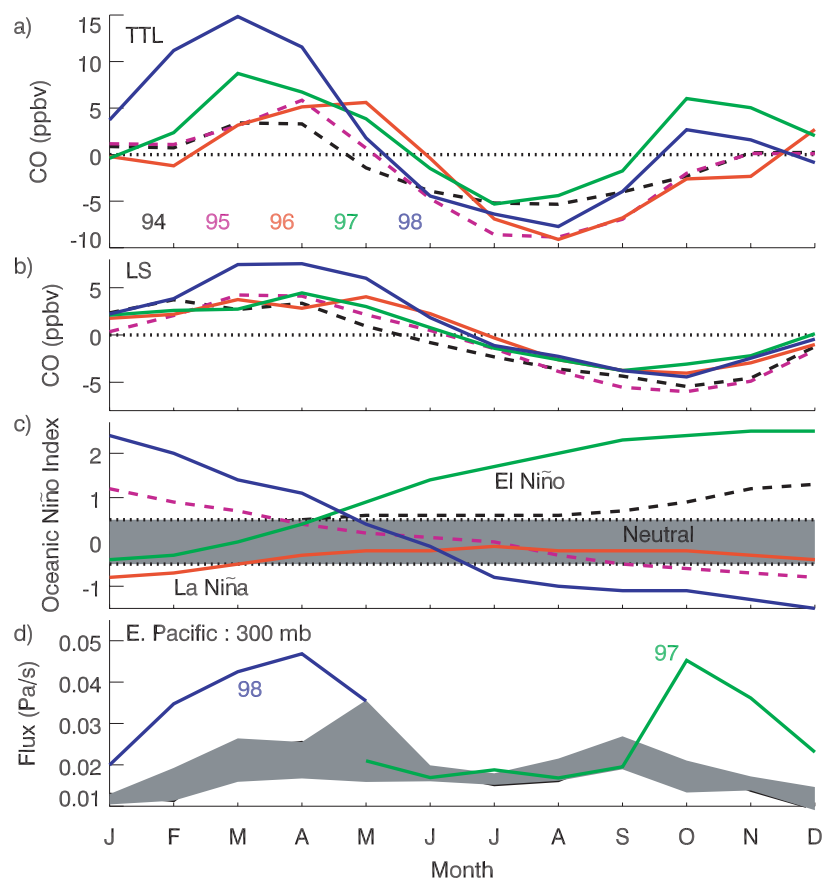

Fig. 19. The average $\mathrm{CO}$ concentration (ppbv) in the (a) TTL and (b) LS for five years (1994-1998) with the 5-yr mean removed. For clarity, 1994 and 1995 are shown as dashed lines. (c) The Oceanic Niño Index (degrees) from the Climate Prediction Center of the National Weather Service, taken as 3-month running mean SST anomalies. The threshold is $+/-0.5^{\circ} \mathrm{C}$ for a warm/cold episode. (d) The simulation's mean convective mass flux $(\mathrm{Pa} / \mathrm{s})$ at $300 \mathrm{mb}$ from $12^{\circ} \mathrm{S}$ to $12^{\circ} \mathrm{N}$ over the eastern Pacific Ocean. The shaded area represents the minimum and maximum fluxes during 1994-1998, excluding the 1997-1998 El Niño event.

simulation (1994-1998) shows that the IAV due to variations in the mean ascent rate and convection is only a few ppbv in the TTL and less than $1.5 \mathrm{ppbv}$ in the LS (not shown), which is much smaller than the IAV due to shifts in the locations in deep convection (i.e. $\sim 10 \mathrm{ppbv}$ in the TTL and $\sim 3 \mathrm{ppbv}$ in the LS in Fig. 19ab).

\section{Conclusions}

In this study, we used the Combo CTM to assess the impact of biomass burning pollution on the composition of the UT/LS. The Combo CTM with GEOS-4-AGCM meteorological data is an appropriate tool for the study of TST of pollution as shown by Strahan et al. (2007) and the reasonable agreement of our simulated CO with MLS and other observations (Sect. 3).

We showed that biomass burning pollution regularly impacts the composition and chemistry of the UT/LS, and that this impact can be substantial (e.g. the 1997 Indonesian wildfires). Reaction with $\mathrm{CO}$ is the primary sink for $\mathrm{OH}$, so the lifetimes of trace gases removed by reaction with $\mathrm{OH}$, in- cluding $\mathrm{CO}$ itself, are lengthened as the $\mathrm{CO}$ concentration increases during the burning seasons. As a result, higher amounts of trace gases are able to cross the tropopause at these times.

We conclude that two pathways of TST, slow ascent in the TTL and quasi-horizontal exchange to the LMS, are of similar importance for the transport of biomass burning pollution. However, the latter pathway delivers the pollution to the LMS, where it most likely returns to the troposphere (Schoeberl et al., 2004); most tropical biomass burning occurs in local spring, a season of strong stratosphere-to-troposphere transport in the extra-tropics, associated with the BrewerDobson circulation. In general, the relative importance of the two TST pathways depends on the lifetime of a trace gas, which is typically longer in the subtropical UT than the TTL where solar radiation and $\mathrm{OH}$ are consistently higher.

Liu and Zipser (2005) and Rossow and Pearl (2007) found that very few tropical convective systems penetrate the tropopause, so this pathway is not likely important for $\mathrm{CO}$ and other trace gases with lifetimes longer than the time-scale of transport to the tropopause via slow ascent. Convection in our simulation did not penetrate the tropical tropopause, yet our simulation reproduces the distributions of MLS observations reasonably well; that is, this pathway is not needed to explain the large-scale features of the observations. However, it may become important locally near convective systems that do occasionally penetrate the tropical tropopause, such as those over central Africa, Indonesia, and South America (Liu and Zipser, 2005).

Both variations in the timing of $\mathrm{CO}$ sources (i.e. emissions and chemical production) and transport (i.e. to the UT by convection and within the TTL/LS by slow ascent) conspire to create a semi-annual oscillation of CO below the TTL that evolves into an annual oscillation in transit to the tropical LS. Seasonal biomass burning in local spring in each hemisphere creates a semi-annual oscillation in tropical CO. In boreal winter, between the $\mathrm{SH}$ and $\mathrm{NH}$ burning seasons, ascent from the TTL to the LS is seasonally high and CO in the northern tropics (i.e. from fossil fuels and $\mathrm{NH}$ burning sources) is at an annual maximum. Consequently, $\mathrm{CO}$ in the TTL/LS remains high between the two burning seasons. In boreal summer, between the $\mathrm{NH}$ and $\mathrm{SH}$ burning seasons, ascent is seasonally low and $\mathrm{CO}$ in the $\mathrm{NH}$ tropics is at an annual minimum. Therefore, $\mathrm{CO}$ during this time is at an annual minimum in the TTL/LS. Randel et al. (2007) used MLS $\mathrm{CO}$ data to conclude that the observed annual cycle provides strong evidence that the oscillation in the LS arises mainly from the annual cycle in the ascent rate from the TTL to the LS; that is, the impact of variations in the sources of $\mathrm{CO}$ are less important. By separating the transport and source contributions to $\mathrm{CO}$ in the UT/LS, we were able to show that both transport and sources are equally important contributors to the observed seasonal cycle.

There are two main sources of IAV in CO in the UT/LS for our study period, 1994-1998. First, year-to-year changes 
in the locations of deep convection loft varying amounts of biomass burning $\mathrm{CO}$ to the UT. The highest concentrations in the UT/LS occurred during the 1997-1998 El Niño, due to enhanced convection over the tropical eastern Pacific Ocean. This shift in the location of deep convection lofted more $\mathrm{CO}$ from South American and African sources to the UT/LS than in other years. Second, year-to-year changes in biomass burning are substantial, especially high during El Niño years when large wildfires typically occur in Indonesia and Central America. The results of our simulations indicate that the IAV in the ascent rate had less impact on the IAV of the composition of the UT/LS than the IAV in the locations of deep convection.

We could not assess the impact of the changes in atmospheric composition (e.g. ozone, water vapor, aerosols) from biomass burning on the dynamics of the UT/LS as we used a CTM. As future work, we plan to conduct sensitivity studies with a coupled chemistry general circulation model to understand the impact of biomass burning pollution on tropical TST.

Acknowledgements. We would like to thank J. Rodriguez and the GMI core modeling team for their efforts which have facilitated our research. We wish to thank E. Nielsen of NASA GMAO for providing us with meteorological fields. We thank A. Douglass and M. Schoeberl for their scientific insight and advice. We gratefully acknowledge those who provided us with their observational data. The Japan Airlines data were provided by H. Matsueda of the Geochemical Research Department, Meteorological Research Institute, Japan. The surface CO data were provided by NOAA GMD. The authors acknowledge the support of the European Commission, Airbus and the Airlines (Lufthansa, Austrian, Air France), who carry free of charge the MOZAIC equipment and have performed maintenance since 1994. MOZAIC is supported by INSU-CNRS (Institut National des Sciences de l'Univers - Centre National de la Recherche Scientifique, France) and by FZJ (Forschungszentrum Jülich, Germany). The GPCP combined precipitation data were developed and computed by the NASA/Goddard Space Flight Center's Laboratory for Atmospheres as a contribution to the GEWEX Global Precipitation Climatology Project. This research was supported by NASA Grant MAP/04-0068-0040.

Edited by: H. Wernli

\section{References}

Adler, R. F., Huffman, G. J., Chang, A., Ferraro, R., Xie, P., Janowiak, J., Rudolf, B., Schneider, U., Curtis, S., Bolvin, D., Gruber, A., Susskind, J., and Arkin, P.: The Version 2 Global Precipitation Climatology Project (GPCP) Monthly Precipitation Analysis (1979-Present), J. Hydrometeor., 4(6), 1147-1167, 2003.

Andreae, M. and Merlet, P.: Emission of trace gases and aerosols from biomass burning, Global Biogeochemical Cycles, 15, 955966, 2001.
Baughcum, S. L., Tritz, T. G., Hernerdon, S. C., and Pickett, D. C.: Scheduled civil aircraft emission inventories for 1992: database development and analysis, NASA CR-4700, Natl. Aeronaut and Space Admin., Washington, D.C., 1996.

Benkovitz, C. M., Scholtz, M. T., Pacyna, J., Tarrason, L., Dignon, J., Voldner, E. C., Spiro, P. A., Logan, J. A., and Graedel, T. E.: Global gridded inventories of anthropogenic emissions of sulfur and nitrogen, J. Geophys. Res., 101(29), 239-29, 253, 1996.

Bey, I., Jacob, D. J., Yantosca, R. M., Logan, J. A., Field, B. D., Fiore, A. M., Li, Q., Liu, H., Mickley, L. J., and Schultz, M.: Global modeling of tropospheric chemistry with assimilated meteorology: Model description and evaluation, J. Geophys. Res., 106(23), 073-23, 095, 2001.

Bian, H. and Prather, M. J.: Fast-J2: Accurate Simulation of stratospheric photolysis in global chemical models, J. Atmos. Chem., 41, 281-296, 2002.

Bloom, S., da Silva, A., Dee, D., Bosilovich, M., Chern, J.-D., Pawson, S., Schubert, S., Sienkiewicz, M., Stajner, I., Tan, W.-W., and $\mathrm{Wu}, \mathrm{M}$.-L.: Documentation and validation of the Goddard Earth Observing System (GEOS) Data Assimilation System Version 4, Technical Report Series on Global Modeling and Data Assimilation 104606, 2005.

Chatfield, R. B., Vastano, J. A., Li, L., Sachse, G. W., and Connors, V. S.: The Great African plume from biomass burning: Generalizations from a three-dimensional study of TRACE A carbon monoxide, J. Geophys. Res. 103(28), 059-77, 1998.

Chatfield, R. B., Guo, Z., Sachse, G. W., Blake, D. R., and Blake, N. J.: The subtropical global plume in the Pacific Exploratory Mission-Tropics A (PEM-Tropics A), PEM-Tropics B, and the Global Atmospheric Sampling Program (GASP): How tropical emissions affect the remote Pacific, J. Geophys. Res., 107(D16), 4278, doi:10.1029/2001JD000497, 2002.

Chen, P.: Isentropic cross-tropopause mass exchange in the extratropics, J. Geophys. Res., 100, 16661-16674, 1995.

Chin, M., Ginoux, P., Kinne, S., Torres, O., Holben, B., Duncan, B., Martin, R., Logan, J., Higurashi, A., and Nakajima, T.: Tropospheric aerosol optical thickness from the GOCART model and comparisons with satellite and sunphotometer measurements, J. Atmos. Sci., 59, 461-483, 2002.

Considine, D. B., Douglass, A. R., Connell, P. S., Kinnison, D. E., and Rotman, D. A.: A polar stratospheric cloud parameterization for the three-dimensional model of the global modeling initiative and its response to stratospheric aircraft, J. Geophys. Res., 105, 3955-3975, 2000.

Dai, A. and Wigley, T. M. L.: Global patterns of ENSO-induced precipitation, Geophys. Res. Lett., 27, 1283-1286, 2000.

Dessler, A. E.: A reexamination of the "stratospheric fountain" hypothesis, Geophys. Res. Lett., 25(22), 4165-4168, 1998.

Dethof, A., O’Neill, A., Slingo, J. M., and Smit H. G. J.: A mechanism for moistening the lower stratosphere involving the Asian summer monsoon, Q. J. R. Meteor. Soc., 125, 1079-1106, Part B., 1999.

Douglass, A. R., Schoeberl, M. R., Rood, R. B., and Pawson, S.: Evaluation of transport in the lower tropical stratosphere in a global chemistry and transport model, J. Geophys. Res., 108(D9), 4259, doi:10.1029/2002JD002696, 2003.

Douglass, A. R., Stolarski, R. S., Strahan, S. E., and Connell, P. S.: Radicals and reservoirs in the GMI chemistry and transport model: Comparison to measurements, J. Geophys. Res., 109, 
D16302, doi:10.1029/2004JD004632, 2004.

Dlugokencky , E. J., Masarie, K. A., Lang, P. M., and Tans, P. P.: Continuing decline in the growth rate of the atmospheric methane burden, Nature, 393, 447-450, 1998.

Duncan, B. N., Martin, R., Staudt, A., Yevich, R., and Logan, J.: Interannual and Seasonal Variability of Biomass Burning Emissions Constrained by Satellite Observations, J. Geophys. Res., 108(D2), 4100, doi:10.1029/2002JD002378, 2003a.

Duncan, B. N., Bey, I., Chin, M., Mickley, L. J., Fairlie, T. D., Martin, R. V., and Matsueda, H.: Indonesian Wildfires of 1997: Impact on Tropospheric Chemistry, J. Geophys. Res., 108(D15), 4458, doi:10.1029/2002JD003195, 2003 b.

Dunlea, E. J. and Ravishankara, A. R.: Kinetic studies of the reactions of O(1D) with several atmospheric molecules, Phys. Chem. Chem. Phys., 6, 2152, doi:10.1039/b400247d, 2004.

Dunkerton, T. J.: Evidence of meridional motion in the summer lower stratosphere adjacent to monsoon regions, J. Geophys. Res., 100, 16 675-16688, 1995.

Evans, M. J and Jacob, D. J.: Impact of new laboratory studies of $\mathrm{N}_{2} \mathrm{O}_{5}$ hydrolysis on global model budgets of tropospheric nitrogen oxides, ozone, and OH, Geophys. Res. Lett., 32, L09813, doi:10.1029/2005GL022469, 2005.

Filipiak, M., Harwood, R., Jiang, J., et al.: Carbon monoxide measured by the EOS Microwave Limb Sounder on Aura: First results, Geophys. Res. Lett., 32, L14825, doi:10.1029/2005GL022765, 2005.

Fishman, J., Fakruzzaman, F., Cros, B., and Nganga, D.: Identification of widespread pollution in the Southern Hemisphere deduced from satellite analyses, Science, 252, 1693-1696, 1991.

Folkins, I., Chatfield, R., Baumgardner, D., and Proffitt, M.: Biomass burning and deep convection in southeastern Asia: Results from ASHOE/MAESA, J. Geophys. Res., 102, 13291$13299,1997$.

Folkins, I., Loewenstein, M., Podolske, J., Oltmans, S. J., and Proffitt, M.: A barrier to vertical mixing at $14 \mathrm{~km}$ in the tropics: Evidence from ozonesondes and aircraft measurements, J. Geophys. Res., 104, 22 095-22 102, 1999.

Folkins, I., Bernath, P., Boone, C., Lesins, G., Livesay, N., Thompson, A. M., Walker, K., and Witte, J. C.: The seasonal cycles of $\mathrm{O}_{3}, \mathrm{CO}$, and convective outflow at the tropical tropopause, Geophys. Res. Lett., 33, L16802, doi:10.1029/2006GL026602, 2006.

Fromm, M., Bevilacqua, R., Servranckx, R., Rosen, J., Thayer, J., Herman, J., and Larko, D.: Pyro-cumulonimbus injection of smoke to the stratosphere: Observations and impact of a super blowup in northwestern Canada on 3-4 August 1998, J. Geophys. Res., 110, D08205, doi:10.1029/2004JD005350, 2005.

Fueglistaler, S., Wernli, H., and Peter, T.: Tropical troposphereto-stratosphere transport inferred from trajectory calculations, J. Geophys. Res., 109, D03108, doi:10.1029/2003JD004069, 2004.

Fu, R., Hu, Y., Wright, J. S., Jiang, J. H., Dickinson, R. E., Chen, M., Filipiak, M., Read, W. G., Waters, J. W., and Wu, D. L.: Short-circuit of water vapor and polluted air to the global stratosphere by convective transport over the Tibetan Plateau, PNAS, doi:10.1073/pnas.0601584103, 2006.

Gettelman, A., de F. Forster, P. M., Fujiwara, M., Fu, Q., Vömel, H., Gohar, L. K., Johanson, C., and Ammerman, M.: Radiation balance of the tropical tropopause layer, J. Geophys. Res., 109, D07103, doi:10.1029/2003JD004190, 2004.
Guenther, A., Hewitt, C. N., Erickson, D., et al.: A global model of natural volatile organic compound emissions, J. Geophys. Res., 100, 8873-8892, 1995.

Hack, J. J.: Parameterization of moist convection in the NCAR Community Climate Model, CCM2, J. Geophys. Res., 99, 55515568, 1994.

Hatsushika, H. and Yamazaki, K.: Stratospheric drain over Indonesia and dehydration within the tropical tropopause layer diagnosed by air parcel trajectories, J. Geophys. Res., 108 (D19), 4610, doi:10.1029/2002JD002986, 2003.

Haynes, P. H. and Shuckburgh, E.: Effective diffusivity as a diagnostic of atmospheric transport. 2. Troposphere and lower stratosphere, J. Geophys. Res., 105(D18), 22 795-22 810, 2000.

Holton, J. R., Haynes, P. H., McIntyre, M. E., Douglass, A. R., Rood, R. B., and Pfister, L.: Stratosphere-Troposphere Exchange, Reviews of Geophysics, 33, 403-439, 1995.

Jacobson, M. Z.: Computation of global photochemistry with SMVGEAR II, Atmos. Environ., 29, 2541-2546, 1995.

Jacob, D. and Bakwin, P.: Cycling of $\mathrm{NO}_{\mathrm{x}}$ in tropical forest canopies and its implications for the global source of biogenic $\mathrm{NO}_{\mathrm{x}}$ to the atmosphere, in Microbial Production and Consumption of Greenhouse Gases, Ed. W.B. Whitman, American Society of Microbiology, Washingoton, D.C., 1991.

Jacob, D. J., Field, B. D., Jin, E., Bey, I., Li, Q. B., Logan, J. A., and Yantosca, R. M.: Atmospheric budget of acetone, J. Geophys. Res., 107(D10), 4100, doi:10.1029/2001JD000694, 2002.

Jacob, D.J., Crawford, J. H., Kleb, M. M., et al.: Transport and chemical evolution over the Pacific (TRACE-P) aircraft mission: Design, execution, and first results, J. Geophys. Res., 108(D20), 9000, doi:10.1029/2002JD003276, 2003.

Jost, H.-J., Drdla, K., Stohl, A., et al.: In-situ observations of midlatitude forest fire plumes deep in the stratosphere, Geophys. Res. Lett., 31, L11101, doi:10.1029/2003GL019253, 2004.

Kar, J., Bremer, H., Drummond, J. R., et al.: Evidence of vertical transport of carbon monoxide from Measurements of Pollution in the Troposphere (MOPITT), Geophys. Res. Lett., L23105, doi:10.1029/2004GL021128, 2004.

Kinnison, D. E., Connell, P. S., Rodriguez, J. M., Rotman, D. A., Considine, D. B., Tannahil, J., Ramaroson, R., Rasch, P. J., Douglass, A. R., Baughcum, S. L., Coy, L., Waugh, D. W., Kawa, S. R., and Prather, M. J.: The Global Modeling Initiative Assessment Model: Application to High-Speed Civil Transport Perturbation, J. Geophys. Res., 106, 1693-1712, 2001.

Levine, J. G., Braesicke, P., Harris, N. R. P., Savage, N. H., and Pyle, J. A.: Pathways and timescales for troposphere-tostratosphere transport via the tropical tropopause layer and their relevance for very short lived substances, J. Geophys. Res., 112, D04308, doi:10.1029/2005JD006940, 2007.

Li, Q., Jiang, J. H., Wu, D. L., et al: Convective outflow of South Asian pollution: A global CTM simulation compared with EOS MLS observations, Geophys. Res. Lett., L14826, doi:10.1029/2005GL022762, 2005.

Lin, S.-J. and Rood, R. B.: Multidimensional flux-form semiLagrangian transport schemes, Mon. Weather Rev., 124, 2046$2070,1996$.

Liu, H., Jacob, D. J., Bey, I., and Yantosca, R. M.: Constraints from ${ }^{210} \mathrm{~Pb}$ and ${ }^{7} \mathrm{Be}$ on wet deposition and transport in a global threedimensional chemical tracer model driven by assimilated meteorological fields, J. Geophys. Res., 106, 12 109-12 128, 2001. 
Liu, C. and Zipser, E. J.: Global distribution of convection penetrating the tropical tropopause, J. Geophys. Res., 110, 2005JD006063, 2005.

Livesey, N. J., Fromm, M. D., Waters, J. W., Manney, G. L., Santee, M. L., and Read, W. G.: Enhancements in lower stratospheric $\mathrm{CH}_{3} \mathrm{CN}$ observed by the Upper Atmosphere Research Satellite Microwave Limb Sounder following boreal forest fires, J. Geophys. Res., 109, D06308, doi:10.1029/2003JD004055, 2004.

Marenco, A., Thouret, V., Nédélec, P., et al.: Measurement of ozone and water vapor by Airbus in-service aircraft: The MOZAIC airborne program, An overview, J. Geophys. Res., 103(D19), doi:10.1029/98JD00977, 1998.

Martin, R. V., Jacob, D. J., Yantosca, R. M., et al.: Global and regional decreases in tropospheric oxidants from photochemical effects of aerosols, J. Geophys. Res., 108(D3), 4097, doi:10.1029/2002JD002622, 2003.

Matsueda, H., Inoue, H. Y., Sawa, Y., Tsutsumi, Y., and Ishii, M.: Carbon monoxide in the upper troposphere over the western $\mathrm{Pa}-$ cific between 1993 and 1996 J. Geophys. Res., 103, 19093$19110,1998$.

Matsueda, H. and Inoue, H. Y.: Aircraft measurements of trace gases between Japan and Singapore in October of 1993, 1996, and 1997, Geophys. Res. Lett., 26, 2413-2416, 1999.

Matsueda, H., Inoue, H. Y., Ishii, M., and Tsutsumi, Y.: Large injection of carbon monoxide into the upper troposphere due to intense biomass burning in 1997, J. Geophys. Res., 104, $26867-$ $26879,1999$.

Metwally, M.: Jet aircraft engine emissions database development: 1992 military, charter and nonscheduled traffic, NASA CR-4684, Natl. Aeronaut. and Space Admin., Washington, D.C., 1995.

Mote, P. W., Rosenlof, K. H., McIntyre, M. E., et al.: An atmospheric tape recorder: The imprint of tropical tropopause temperatures on stratospheric water vapor, J. Geophys. Res., 101, 3989-4006, 1996.

Nedelec, P., Cammas, J.-P., Thouret, V., et al.: An improved infrared carbon monoxide analyser for routine measurements aboard commercial Airbus aircraft: technical validation and first scientific results of the MOZAIC III programme, Atmos. Chem. Phys., 3, 1551-1564, 2003,

http://www.atmos-chem-phys.net/3/1551/2003/.

Nedelec, P., Thouret, V., Brioude, J., et al.: Extreme CO concentrations in the upper troposphere over northeast Asia in June 2003 from the in situ MOZAIC aircraft data, Geophys. Res. Lett., 32, L14807, doi:10.1029/2005GL023141, 2005.

Newell, R. E. and Gould-Stewart, S.: A Stratospheric Fountain?, American Meteorological Society, 38, 2789-2796, 1981.

Novelli, P. C., Steele, L. P., and Tans, P. P.: Mixing ratios of carbon monoxide in the troposphere, J. Geophys. Res., 102, 12855 $12861,1992$.

Novelli, P. C., Masarie, K. A., and Lang, P. M.: Distributions and recent changes in carbon monoxide in the lower troposphere, J. Geophys. Res., 103, 19 015-19 033, 1998.

Olsen, M. A., Schoeberl, M. R., and Douglass, A. R.: Stratospheretroposphere exchange of mass and ozone, J. Geophys. Res., 109, D24114, doi:10.1029/2004JD005186, 2004.

Olson, J.: World ecosystems (WE1.4): Digital raster data on a 10 minute geographic 1080 × 2160 grid, in Global ecosystems database, version 1.0: Disc A, Ed. NOAA Natl. Geophys. Data Center, Boulder, CO, 1992.
Piccot, S., Watson, J., and Jones, J.: A global inventory of volatile organic compound emissions from anthropogenic sources, J. Geophys. Res., 97, 9897-9912, 1992.

Pickering, K. E., Wang, Y. S., Tao, W. K., Price, C., and Muller, J. F.: Convective transport of biomass burning emissions over Brazil during TRACE A, J. Geophys. Res., 101, 23 993-24 012, 1996.

Pickering, K. E., Wang, Y. S., Tao, W. K., Price, C., and Muller, J. F.: Vertical distributions of lightning $\mathrm{NO}_{\mathrm{x}}$ for use in regional and global chemical transport models, J. Geophys. Res., 103(D23), 31 203-31 216, 1998.

Price, C. and Rind, D.: A simple lightning parameterization for calculating global lightning distributions, J. Geophys. Res., 97, 9919-9933, 1992.

Price, C., Penner, J., and Prather, M.: $\mathrm{NO}_{\mathrm{x}}$ from lightning, Part I: Global distribution based on lightning physics, J. Geophys. Res., 102, 5929-5941, 1997.

Prinn, R. G., Huang, J., Weiss, R. F., et al.: Evidence for variability of atmospheric hydroxyl radicals over the past quarter century, Geophys. Res. Lett., 32, L07809, doi:10.1029/2004GL022228, 2005.

Randel III, W. J., Zawodny, J. M., Oltmans, S. J.: Seasonal variation of water vapor in the lower stratosphere observed in Halogen Occultation Experiment data, J. Geophys. Res., 106, 14 313-14 325, 2001.

Randel III, W. J.: A large annual cycle in ozone above the tropical tropopause linked to the Brewer-Dobson circulation, J. Atmos. Sci., accepted, 2007.

Rasch, P. J., Mahowald, N. M., and Eaton, B. E.: Representations of transport, convection, and the hydrologic cycle in chemical transport models: Implications for the modeling of short-lived and soluble species, J. Geophys. Res., 102, 28 127-28 138, 1997.

Ravishankara, A. R., Dunlea, E. J., Blitz, M. A., et al.: Redetermination of the rate coefficient for the reaction of $\mathrm{O}\left({ }^{1} \mathrm{D}\right)$ with $\mathrm{N}_{2}$, Geophys. Res. Lett., 29 (15), 1745, doi:10.1029/2002GL014850, 2002.

Rosenlof, K. H.: Seasonal cycle of the residual mean meridional circulation in the stratosphere, J. Geophys. Res., 100, 5173-5191, 1995.

Rossow, W. and Pearl, C.: 22-Year survey of tropical convection penetrating into the lower stratosphere, Geophys. Res. Lett., 34, L04803, doi:10.1029/2006GL028635, 2007.

Rotman, D. A., Tannahill, J. R., Kinnison, D. E., et al.: Global Modeling Initiative assessment model: Model description, integration, and testing of the transport shell, J. Geophys. Res., 106, 1669-1691, 2001.

Sander, S., Friedel, R., Ravishankara, A., et al.: Chemical kinetics and photochemical data for use in atmospheric studies, Evaluation no. 14, JPL Publ., 02-25, 2003.

Schoeberl, M. R., Douglass, A. R., Zhu, Z., and Pawson, S.: A comparison of the lower stratospheric age spectra derived from a general circulation model and two data assimilation systems, J. Geophys. Res., 108(D3), 4113, doi:10.1029/2002JD002652, 2003.

Schoeberl, M. R., Douglass, A. R., Hilsenrath, E., et al.: Earth observing systems benefit atmospheric research, EOS, 85, 177178, 2004.

Schoeberl, M. R., Duncan, B. N., Douglass, A. R., Waters, J., Livesey, N., Read, W., and Filipiak, M.: The carbon 
monoxide tape recorder, Geophys. Res. Lett., 33, L12811, doi:10.1029/2006GL026178, 2006.

Sherwood, S. C.: A stratospheric "drain" over the Maritime Continent, Geophys. Res. Lett., 27, 677-680, 2000.

Spivakovsky, C. M., Logan, J. A., Montzka, S. A., et al.: Threedimensional climatological distribution of tropospheric $\mathrm{OH}$ : Update and evaluation, J. Geophys. Res., 105(D7), 8931-8980, 2000.

Staudt, A. C., Jacob, D. J., Logan, J. A., Bachiochi, D., Krishnamurti, T. N., and Poisson, N.: Global chemical model analysis of biomass burning and lightning influences over the South Pacific in austral spring, J. Geophys. Res., 107(D14), 4200, doi:10.1029/2000JD000296, 2002.

Strahan, S. E., Duncan, B. N., and Hoor, P.: Evaluation of transport in the lowermost stratosphere using observationally-derived diagnostics, Atmos. Chem. and Phys. Discuss., 7, 2435-2445, 2007.

Thompson, A. M., Pickering, K. E., McNamara, D. P., Schoeberl, M. R., Hudson, R. D., Kim, J. H., Browell, E. V., Kirchoff, V. W. J. H., and Nganga, D.: Where did tropospheric ozone over southern Africa and the tropical Atlantic come from in October 1992? Insights from TOMS, GTE TRACE A, and SAFARI 1992, J. Geophys. Res., 101, 24 251-24 278, 1996.

Tyndall, G. S., Cox, R. A., Granier, C., Lesclaux, R., Moortgat, G. K., Pilling, M. J., Ravishankara, A. R., and Wallington, T. J.: Atmospheric chemistry of small organic peroxy radicals, J. Geophys. Res., 106(D11), 12 157-12 182, 10.1029/2000JD900746, 2001. van der Werf, G., Anderson, J., Giglio, L., Collatz, G., and Kashibhatla, P.: Interannual variability in global biomass burning emissions from 1997 to 2004, Atmos. Chem. and Phys., 6, 34233441, 2006.

Wang, Y., Jacob, D. J., and Logan, J. A.: Global simulation of tropospheric $\mathrm{O}_{3}-\mathrm{NO}_{\mathrm{x}}$-hydrocarbon chemistry: 1. Model formulation, J. Geophys. Res., 103, 10713-10 725, 1998.

Wesely, M. L., Cook, D. R., Hart, R. L., and Speer, R. E.: Measurements and parameterization of particulate sulfur dry deposition over grass, J. Geophys. Res., 90, 2131-2143, 1985.

Wild, O., Zhu, X., and Prather, M. J.: Fast-J: Accurate simulation of in- and below-cloud photolysis in tropospheric chemical models, J. Atmos. Chem., 37, 245-282, 2000.

Yevich, R. and Logan, J. A.: An assessment of biofuel use and burning of agricultural waste in the developing world, Global Biogeochem. Cycles, 17(4), 1095, doi:10.1029/2002GB001952, 2003.

Zhang, G. J. and McFarlane, N. A.: Sensitivity of climate simulations to the parameterization of cumulus convection in the Canadian Climate Centre general circulation model, Atmos. Ocean, 33, 407-446, 1995.

Ziemke, J.R., Chandra, S., Duncan, B. N., Froidevaux, L., Bhartia, P. K., Levelt, P. F., and Waters, J. W.: Tropospheric ozone determined from Aura OMI and MLS: Evaluation of measurements and comparison with the Global Modeling Initiative's Chemical Transport Model, J. Geophys. Res., 111, D19303, doi:10.1029/2006JD007089, 2006. 